\title{
DHAHIRATU AL-ISTIKHDAM AL-SHUROH AL-RUMZIYAH FI MAWAQI AL-TAWASHUL AL-IJTIMAI'I WA DAURIHA FI AL-TA'THILI AL-LUGHAWI LADA THALABAH AQSAM AL-LUGHAH AL-ARABIYAH FI JAMIAH AL-JAUFI
}

\author{
Ahmad Ibrahim Bani Atha
}

\author{
bani_ata2@yahoo.com \\ Arabic Language Department, Jouf University \\ Saudi Arabia
}

\begin{abstract}
This study aimed to know the habits of the use of symbolism in social media and its impact on the language among students of Arabic language section at Jouf University. Youth category is the largest group exposed to linguistic decline because of being hooked on social media. This has created negative impressions of their language, as a generation may emerge far from his language and identity, unable to express what is confused, the transition from verbal symbols to symbolic leads to shifts in meaning and function, and the reduction of sensations in the yellow faces. With its symbolism, it serves only general purposes, initial and superficial connotations, simple words and sentences. The use of language in everyday conversations to communicate with relatives and entertainment is one of the most motivating habits of language revolt, especially the positive impression it has left on young people for their ease of expression, attractiveness and simplicity, saving effort, shortening speech, and modernity, all of which led to dumping in their language use. It can, therefore, lead to the development of encrypted language dictionaries, change the pattern of thinking, hasten the formation of false personal impressions, and lead to introverts and psychological isolation; therefore, young people fall victim to linguistic decay.
\end{abstract}

Keywords: Uslub, al-Iltifât, Balagah.

$$
\begin{aligned}
& \text { العربيزية، التي تقومُ على تناوبِ بعضِ الأرقاح والحروفِ الإبحليزيةِ } \\
& \text { مع بعضِ الحروفِ العربيةِ، بل وبتاوز الأمرُ ذلك إلى ظهور ما } \\
& \text { يسمى بالإيموجي (الصورة الرمزية) وهي عبارةٌ عن أشكالٍ } \\
& \text { وضعتْ أولُ أمرها للتعبير عن المشاعر والأحاسيس، ولتقديم } \\
& \text { إطارٍ للحالة الشعورية للشخص، فقد وضعها اليابانيون ولاقت } \\
& \text { انتشاراً كبيراً عندهم، وتنوعت وتعددت دلالاكُّا ومعانيها. } \\
& \text { وبما أنَّ أكثرَ فئةٍ استمالتها هذه الشبكاتُ الجلديدةُ هي ولي } \\
& \text { فئة الشبابِ، فقد جاءت هذه الدراسة، لتكشفَ النقابَ عن } \\
& \text { خطورة استخدام الصورة الرمزيةِ على اللغة، ولإعادةٍ تصحيح } \\
& \text { وضعياتٍ لغويةٍ وقناعاتِ تعبيريةٍ لدى هذه الفئةِ. }
\end{aligned}
$$

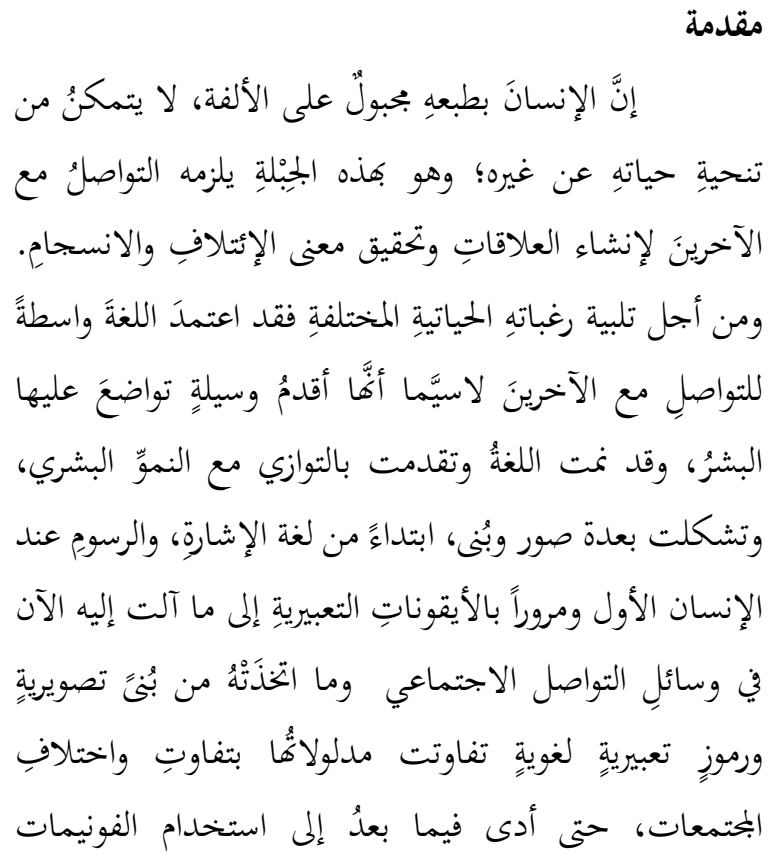


الشخص محبوسا على الفئة التي يتواصل معها، ويؤدي

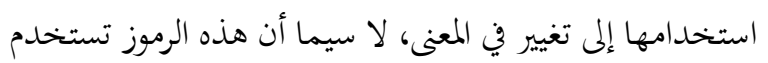
في موضوعات ضيقة، وتقلل من حرارة المشاعر المفعمة في

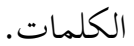

أهمية الدراسة:

تكمن أهميتها في أنَّ أكثر فئة استمالتها هذه الشبكات

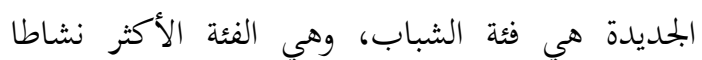
واستخداما للرموز التعبيرية في وسائل التواصل الاجتماعي. إعادةٍ تصحيح وضعياتٍ لغويةٍ وقناعاتٍ تعبيريةٍ لدى فئة الشباب. أهمية وسائل التواصل الاجتماعي لكوغها مظهر من مظاهر

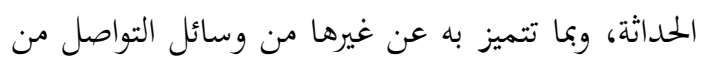
حيث التفوق والإتقان والإجادة، لا سيما أها قريبة المنال

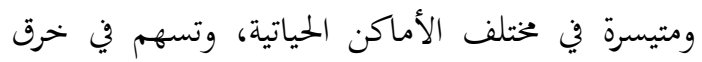

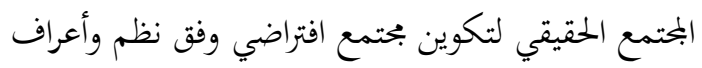
ومفاهيم جديدة، سواء على المستوى الكتابي أو الثقافي

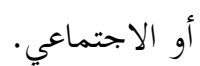
الكشف عن مدى خطورة استخدام الرموز التعبيرية كلغة اتصالية بديلة في مواقع التواصل الاجتماعي.

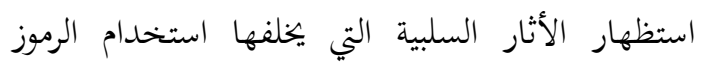
التعبيرية على النظام اللغوي لدى الناطق من حيث الأداء الكلامي والصوتي.

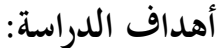

1- التعرف إلى طبيعة اللغة التي يستخدمها طلبة أقسام اللغة العربية في جامعة الجحوف في مواقع التواصل الاجتماعي.

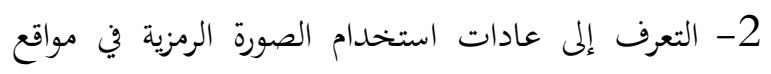
التواصل الاجتماعي من قبل طلبة أقسام اللغة العربية في جامعة الجوف. 3- التعرف إلى دوافع استخدام الصورة الرمزية التعبيرية في

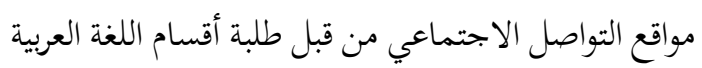
في جامعة الجوف.

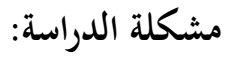
تتحدد مشكلة الدراسة بالسؤال البحثي التالي: هل لظاهرة استخدام الصورة الرمزية في مواقع التواصل الاجتماعي دور في التعطيل اللغوي لدى طلبة أقسام اللغة العربية في جامعة الجوف؟ وينبثق من السؤال الرئيس الأسئلة

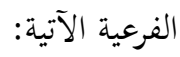

ما هي عادات استخدام الصورة الرمزية في مواقع التواصل

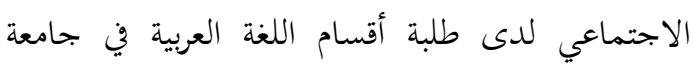

$$
\text { الجوف؟ الإعناع }
$$

ما هي أسباب استخدام الصورة الرمزية في مواقع التواصل

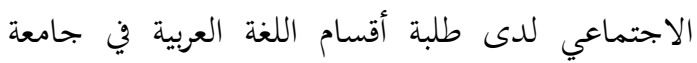

$$
\text { الجوف؟ الاجناع }
$$

ما هو أثر استخدام الصورة الرمزية في مواقع التواصل الاجتماعي على اللغة لدى طلبة أقسام اللغة العربية في

$$
\text { جامعة الجوف؟ الدمبع }
$$

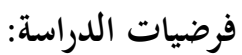

إن إنكالية استخدام الصورة الرمزية في مواقع التواصل الاجتماعي، ودورها في التعطيل اللغوي لدى طلبة أقسام اللغة

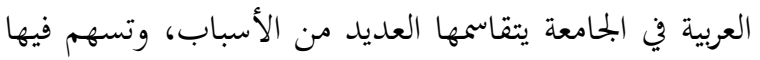

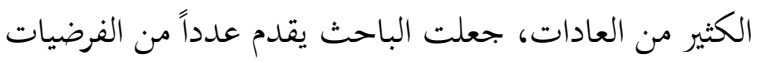
التي قد توصله إلى نتائج مرفقة بحلول قد بتحد من يأخذ بها: الفرضية الأولى: قد يكون سبب الإشكالية في عادات

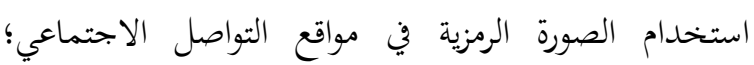
والإغراق في استخدامها في المحاورات اليومية للتسلية أو لغاية التهرية التواصل مع الأقارب والأصدقاء ولمعرفة المعلومات. الفرضية الثانية: قد يكمن الإشكال في أسباب استخدام

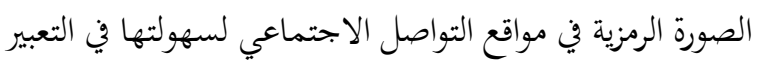

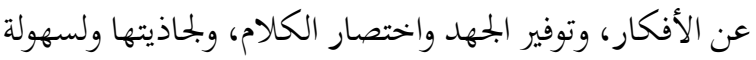
الفهم، ولكوها تعبر عن البنية الشخصية، وللتنقيب عن الحداثة والعصرنة. الفرضية الثالثة: قد تعزى الإشكالية إلى تأثير استخدام الصورة

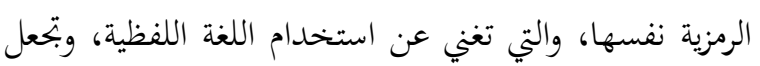


محمود شاكر: "وما كانت أداة الصوت، وهي الحلق واللسان وما يكتنفها، هي بطبيعتها مختلفة في الناس على تباينهم منذ ومن

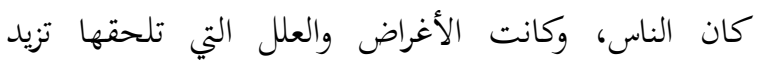
الاختلاف كثرة وشدة، كانت الأصوات المعبرة عن الأغراض عرضة للتباين والاختلاف أيضا... والجماعات أيضا خحاضعة

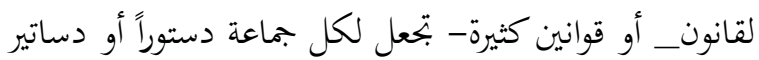

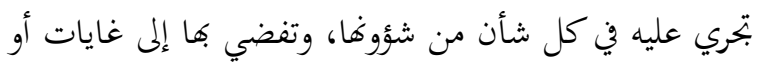

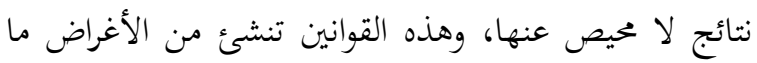
تصبح به الجماعة فئة ذات حضارة مدنية على اختلاف

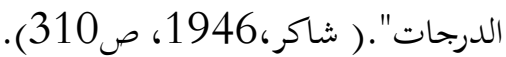

ووصفها ابن خلدون بقوله: " اعلم أنَّ اللغات كلَّها ملكاتُّ شبيهةٌ بالصناعة ، إذ هي ملَكاتُّ في اللسان ، للعبارة

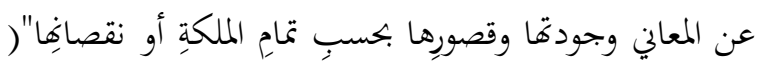
ابن خلدون، 1984، 722/2 فقد عمد إلى إلى فك القيود التي يمكن أن يقال: تفرضها اللغة على التفكير ، تنبه من جانب

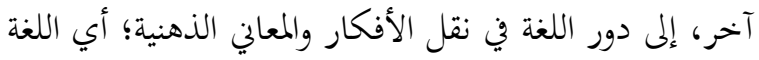

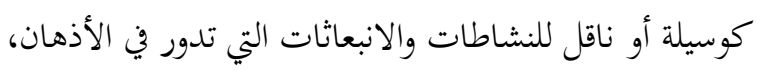

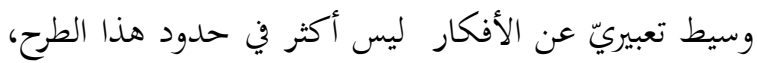
فعملية التفكير عند ابن خلدون، يلزمها استعمال اللغة، والتي

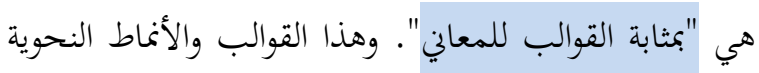
ما هي إلا تصوير للواقع والعالم حسب ما يراه الفرد، إنما رؤية

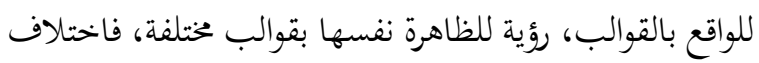

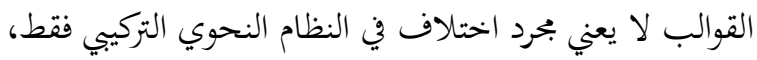

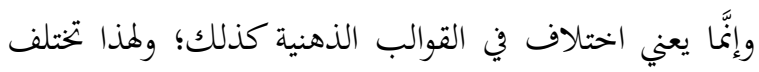
تصورات الإنسان عن العالم الخارجي، تبعا لاختلاف القوالب اللغوية، واللغة تصنيف وترتيب لتيار التجربة العملية التي ينتجها نظام بجتمع معين، والناس يؤدون المواقف بطريقة تشبه الطريقة

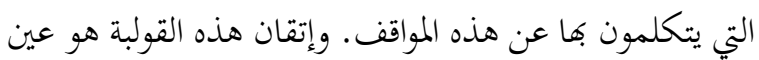
"ملكة اللسان" تُتَحصَّل بالسماع والمران والدربة، فالتعبير عن هُه

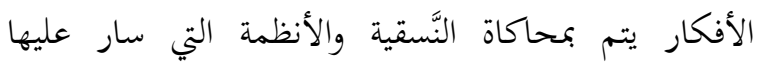
الآخرون، وهذا ما رمى إليه ابن خلدون عند وصفه الألفاظ بالقوالب، فاللغة عند ابن خلدون لا تسيطر على الفكر وتقيده، وإنَّا تحدد طرائق التعبير عنه (بني عطا، 2018م)
4- التعرف إلى أثر استخدام الصورة الرمزية على اللغة في مواقع التواصل الاجتماعي لدى طلبة أقسام اللغة العربية في

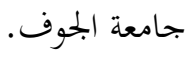

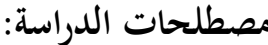

مواقع التواصل الاجتماعي: مواقع إلكترونية تتيح للأفراد خلق صفحة خاصة بهم يقدمون فيها لمحة عن شخصياتم أمام

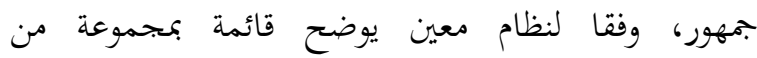
المستخدمين الذين يتشاركون معظم الاتصال، مع إمكانية الاطلاع على صفحاقم الخاصة (القبرصي، ومظفر، 2011، ص2). أما المفهوم الإجرائي، فهي مواقع اجتماعية تفاعلية

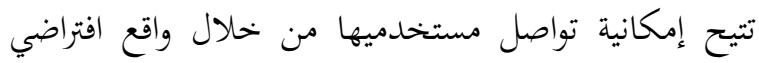

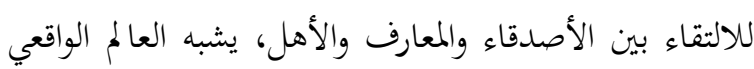

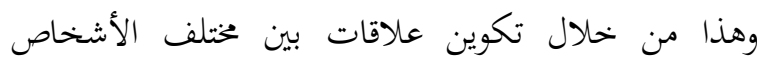
باختلاف أعمارهم، وجنسهم، بتمعهم نشاطات، واهتمامات مشتركة، كما أغها نوافذ للتعبير عما يدور في عقول ونفوس الأشخاص، من خلال تبادل المعلومات والمعارف والصور

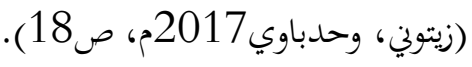

الصورة الرمزية: عبارة عن رمز عنصري ضمن بحموعة متعارف عليها من الرموز، يهدف إلى تمثيل محرف مقروء، وذلك بغرض الكتابة، وبالتالي التعبير عن الأفكار والمفاهيم، وهي علامة رمزية ونوعية وميزة، تشكل بمجملها معنى متكامل (شحيبر،

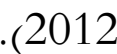

اللغة: عرف ابن جني اللغة وحدها بأها: "أصوات يعبر بها

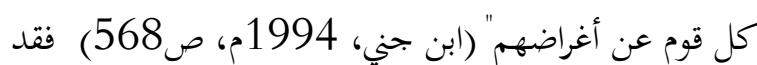
أكد على الطبيعة الصوتية للغة، ووظيفتها الاجتماعية في التعبير ونقل الفكر(حجازي 1973م، ص ص 9، 10، وهذا المفهوم الدقيق ينسجم في جوهره مع هوية مفهوم النظرية النسبية عند سابير وبنيامين وورف، فهو يعلل وجود الرموز الصوتية لتمثيلها

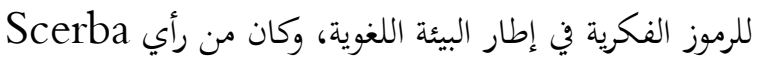

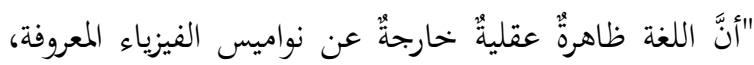
وصرح بأن: "الأصوات لا وجود لها، وإنَّا تحيا بأمثلتها، وصورها العيزياء المعروهة في العقل" (Kramsky. 1974.p41) ويقول الدكتور 
وال يسوسها فهم معطلون، وقد عطلوا: أي أهملوا، وبئر معطلة

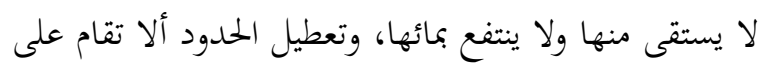

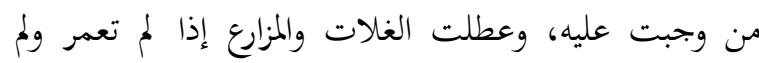

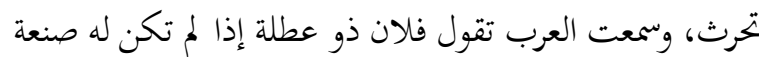

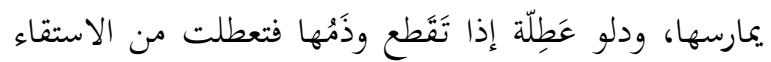

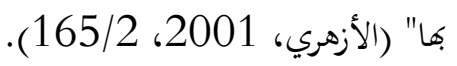

قال ابن فارس: (عطل) العين والطاء واللام أصل صحيح واحد يدل على خلو وفراغ؛ تقول عطلت الدار، ودار معطلة. ومتى تركت الإبل بلا راع فقد عطلت، وكذلك البئر إذا لم تورد

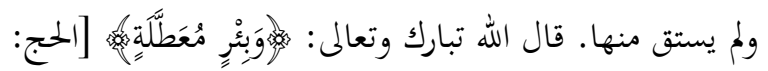

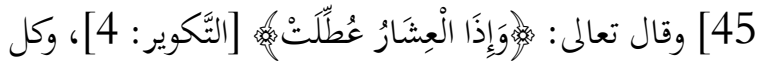
شيء خلا من حافظ فقد عطل، من ذلك تعطيل الثغور وما

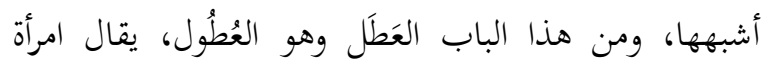

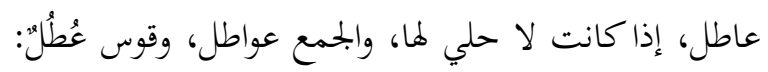

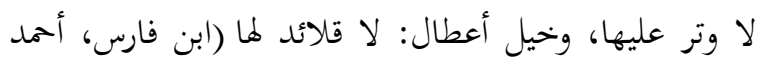

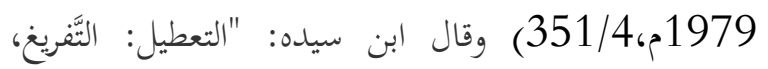

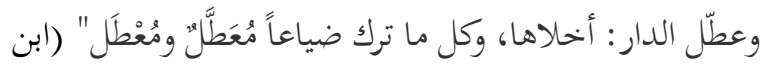

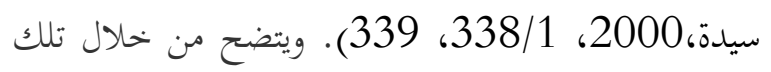

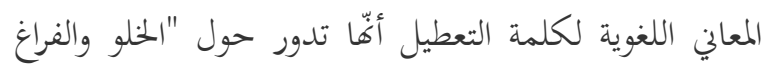
والترك"

جامعة الجوف: جامعة حكومية سعودية تقع بين مدينتي سكاكا ودومة الجندل بمنطقة الجحوف بالمملكة العربية السعودية وهي تحت إشراف وزارة التعليم، أُنشئت الجامعة بتاريخ 12- 125-1426 هـ. وكانت تسمى فرع جامعة الملك سعود بمنطقة

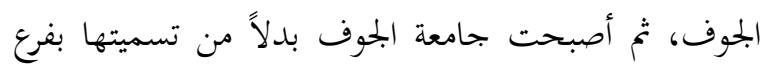

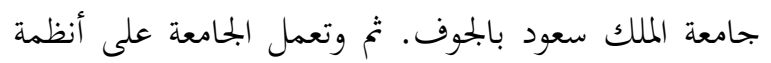
وقوانين التعليم العالي المعمول بها في المملكة العربية السعودية، تُقام المدينة الجحامعية على مساحة 7,200,000 متر مُقابل المعابل

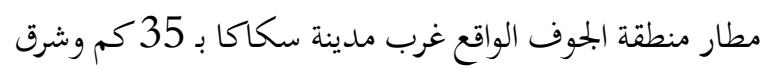

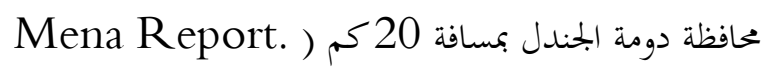
.(12 May 2011
ويعرفها سابير بقوله: "Language is purely human and non-instinctive method of communicating (EDWARD, S. 1921.p32) means of voluntarily produced by ideas, emotions and desires symbols. الاتصال بوصفه الهدف الذي يتوخاه المرء من استخدام اللغة، فاللغة عند سابير إنسانية خالصة، وليست غريزية، تستهدف بلهن توصيل الأفكار والمشاعر والرغبات من خلال نظام من الرموز

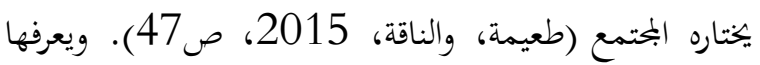
تراجر بقوله: "Arbitrary vocal symbols by means of which the Language is a system of members of a society interact in terms of their culture (TRAGER, G.L. 1949) اللغة هنا نظام من الرموز المتعارف عليها،

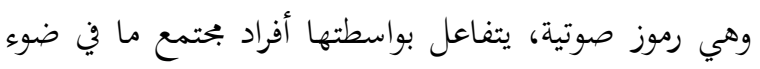

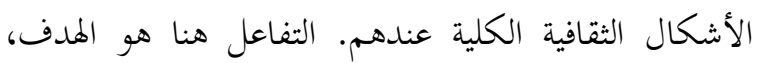
والتفاعل كما نعلم درجة أعلى من الاتصال. فإذا كان الاتصال

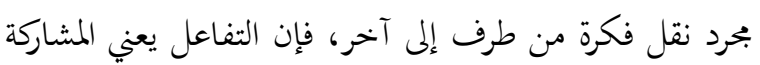

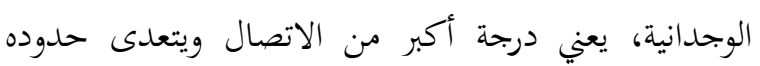

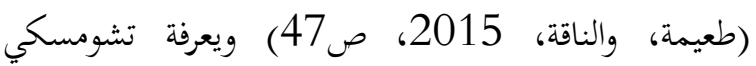
Length Language is a set finite or" infinite of sentences, each finite in and constructed out of a finite set of elements"(N. Chomsky, 1957) واللغة في رأيه هنا فئة، أو بحموعة من الجمل المحدودة، أو

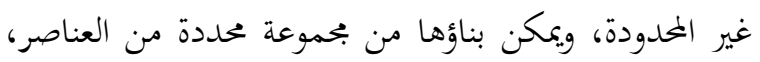

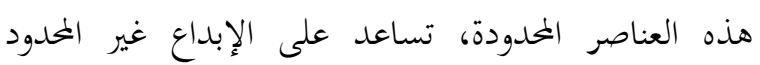

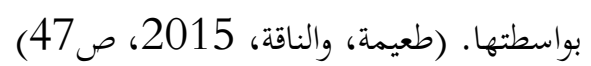
التعطيل: قال الخليل بن أحمد: "امرأة عاطل بغير هاء: لا حلي

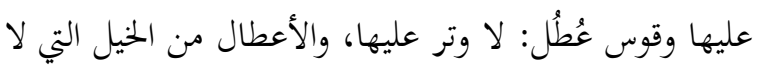

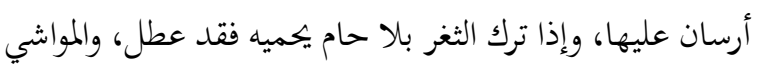
إذا أهملت بلا راع فقد عطلت، وكذلك الرعية إذا لم يكن لها 
التعبيرية بمختلف أنواعها كشيفرة الإيموجي، وشيفرة رموز

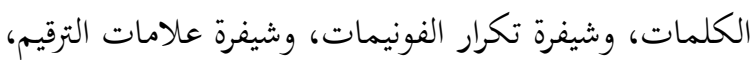
وشيفرة الحروف الإنحليزية، بينما جاءت هذه الدراسة لتخصص ولتفرد رمزا من هذه الرموز في الاستقصاء والدراسة وهو الصورة الرمزية (الإيموجي)؛ لأها الأكثر شيوعا والأخطر، ونموذجا

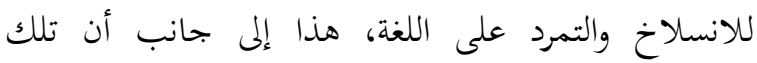
الدراسات لم تستظهر أثر الرموز التعبيرية على اللغة استظهارا

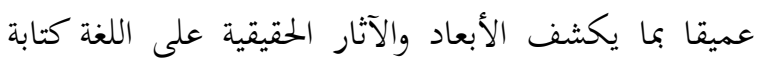
واستعمالا، بل اكتفت باستعراض الفحص الإحصائي الخالص

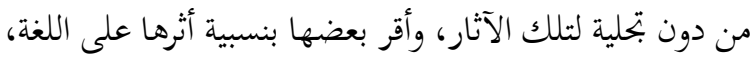
بينما جاءت هذه الدراسة لتسلط الضوء على اللغة أولا، ابتداء باستبانة الدراسة التي ضمنت أدوات لغوية قادرة على رصد المدارات حول حقيقة هذه الأيقونات.

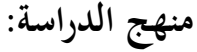

اعتمد الباحث في هذه الدراسة على المنهج التحليلي

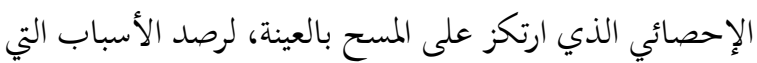
أدت إلى تعطيل اللغة عند هذه الفئة من الشباب واستبدالها

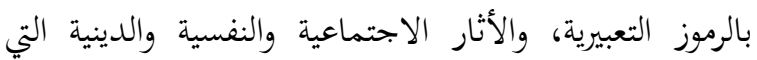
خلفها عند هذه الفئة. أدوات جمع معلومات الدراسة: قام الباحث بإعداد استبانة لاستطلاع آراء الطلاب والطالبات حول ظاهرة استخدام الصورة الرمزية في مواقع التواصل الاجتماعي في الفصل الدراسي الثاني من العام الجامعي

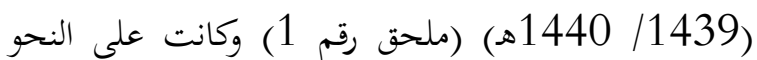

1- طُرِح تسعة عشر سؤالا على طلاب وطالبات أقسام اللغة

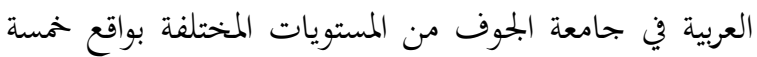

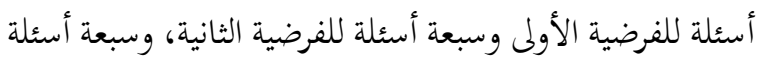
للفرضية الثالثة، ولتسهيل الردود على المقياس تم تحديد خمسة

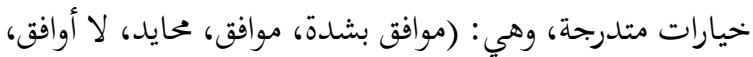
لا أوافق بشدة).

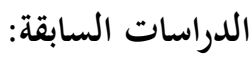
1- قام الباحث الهامي حسام، المملكة العربية السعودية (2015) بدراسة عنواها "سيميولوجيا التواصل الاجتماعي، دراسة تحليلية لبنية الرموز غير اللفظية على موقع فيس بوك "مقدم لمؤتمر بعنوان" وسائل التواصل الاجتماعي التطبيقات والإشكالات المنهجية، الرياض المملكة العربية السعودية.

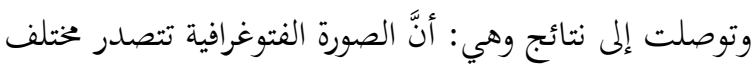

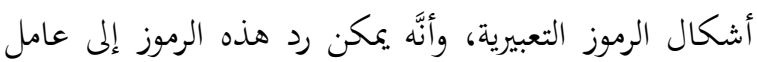
اجتماعي، وقد عمد البعضُ إلى استخدام هذه الرموز لإضفاء بعض سمات وملامح معينة على النص المكتوب.

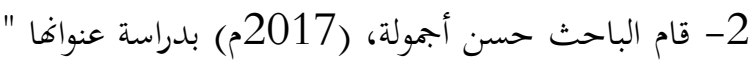

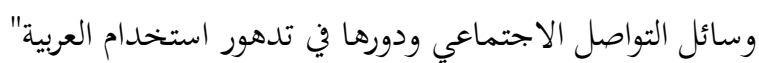
هدفت إلى تسليط الضوء على الدور السلبي الذي لهذه الوسائل على استخدام اللغة، والأسباب وراء ذلك، وخرجت بنتائج

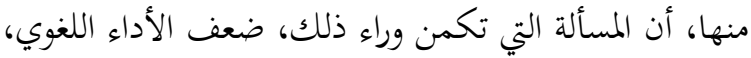

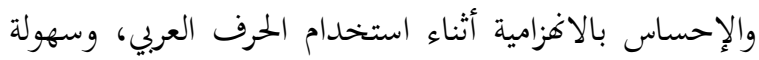
العامية.

3- قامت الباحثة خديجة زيتوني، وفاطمة الزهراء حرباوي، جامعة محمد بو ضياف__المسيلة، كلية العلوم الإنسانية والاجتماعية، قسم اللغة العربية الجزائر، (2017/2016مهم) بدراسة عنواها" أثر استخدام الرموز التعبيرية في شبكات التواصل الاجتماعي على اللغة_ الفيس بوك أنموذجا_" هدفت

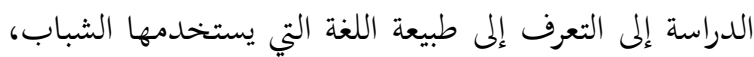

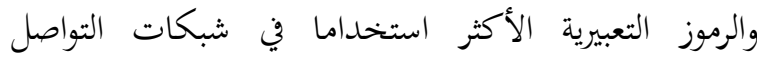
الاجتماعي والأهداف المقققة من وراء استخدام هذه الرموز، وخرجت بنتائج منها: أن أغلب الشباب يستخدمون مواقع التواصل الاجتماعي وخاصة الإناث للتواصل بين الأقارب

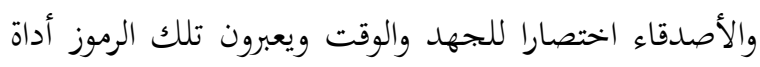
تواصلهم وتأثيرها على اللغة نسبي. التعليق على الدراسات السابقة:

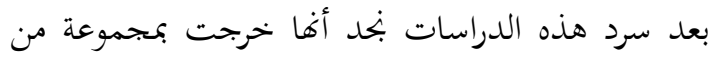
النتائج ينحصر جلها في الكشف عن الرموز التعبيرية الأكثر استخداما في وسائل التواصل الاجتماعي، فقد تناولت الرموز 
1- شيفرة الإيموجي: كلمة "إيموجي" هي كلمة يابانية مكونة

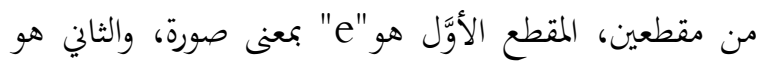

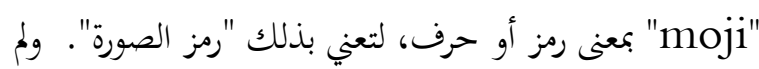

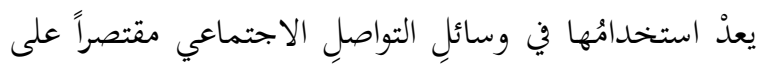

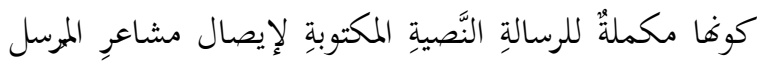

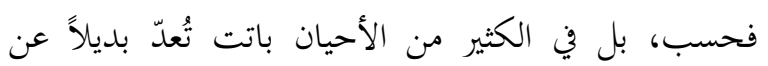

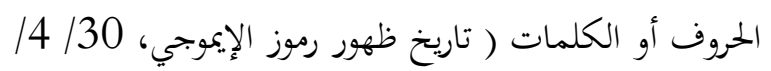

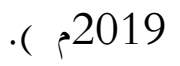
لمُ تقتصر شهرةٌ "الإيموجي" على وسائل التواصل

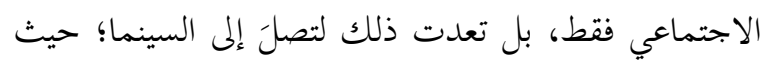

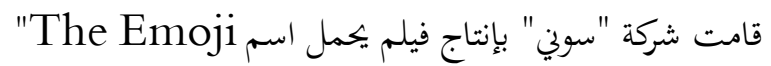
Movie"

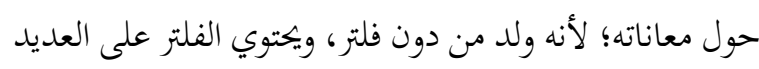

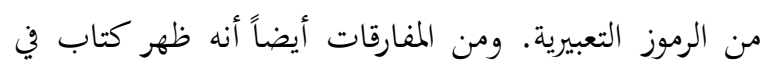

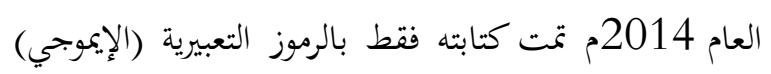
دون استخدام أية كلمات، وهي رواية إبخليزية، حملت عنوان التمان

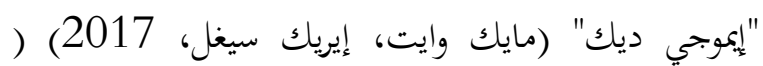

.(Andrew. 2018

وفيما يأتي عرض موجز لبعض الصور الرمزية (الإموجي)

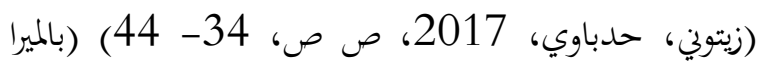

\begin{tabular}{|c|c|}
\hline المعنى الكلامي الذي يؤديه & مز التعبيري \\
\hline وأوقاها مغلقة، وفم مع دموع مفتوأ العيون المنحنية التي هي في معظم وأسنان علوية بارزه من & \\
\hline 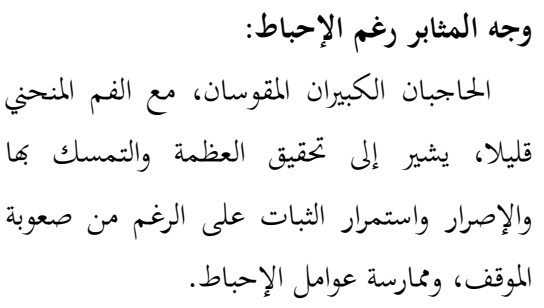 & \\
\hline والمقه الإرهاق والتعب: & \\
\hline
\end{tabular}

2- قُدمت الاستبانة لأربعة محكمين من أعضاء هيئة التدريس من ذوي الاختصاص في الجامعة وخارجها لتحكيمها، ومراعاة

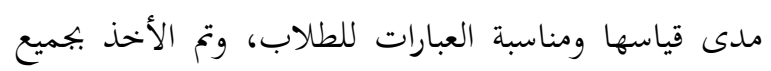
التعديلات التي أشاروا إليها. ثم عرضت الاستبانة بصورتا

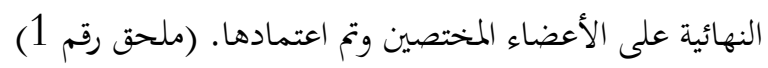

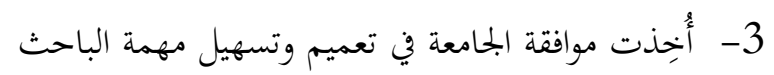

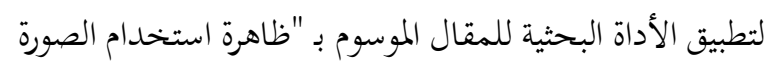

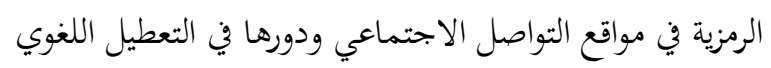

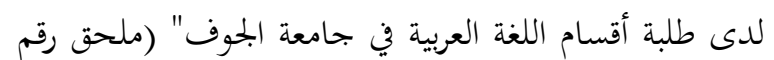

4- تم تحميل الاستبانة برابط عن طريق( Gmail ) الخاص بجامعة الجوف، وإرساله إلى الطلاب والطالبات على نظام طالئام

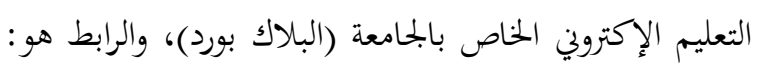
اللغوي: المبحث الأول: الصورة الرمزية بين الشيفرة والتعطيل أولا: لمحة تاريخية: استُخدمت الصورة الرمزية من قبل مشغلي شبكاتِ الهاتفِ

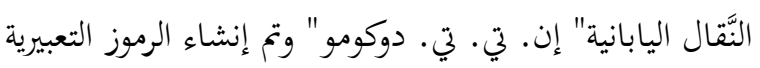
الأول عام 1999 في اليابان من قبل "شجيتاكا كوريتا"، فقد الئد

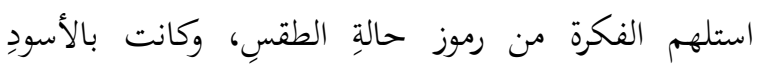

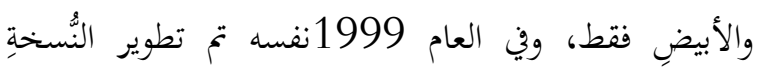

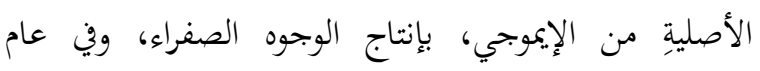

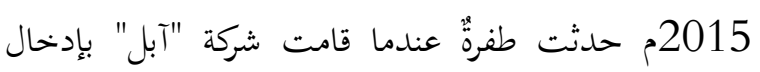

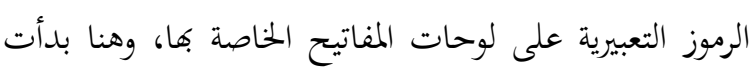

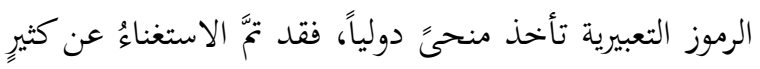
من الكلمات التقليدية التي تعبر عن المشاعر والأحاسيس.

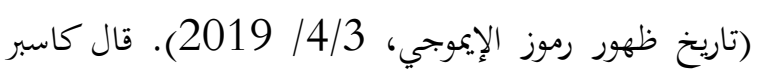

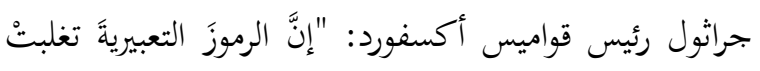

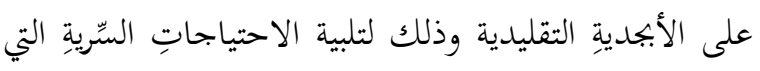

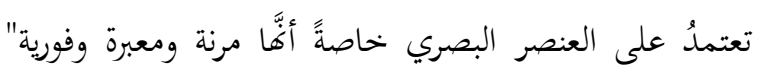

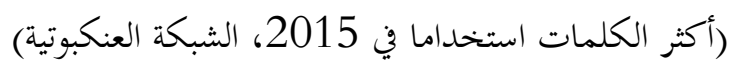
ثانياً: أنواع الشيفرة اللغوية على مواقع التواصل الاجتماعي. 
تكرار السؤال فإنه يلجأ إلى كتابة علامة السؤال فقط. ومثال

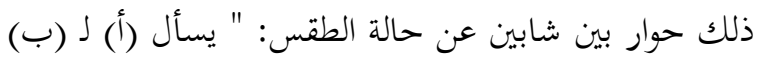
هل تابعت النشرة الجوية؟ (ب) نعم. يقول (ب): (؟). فهو

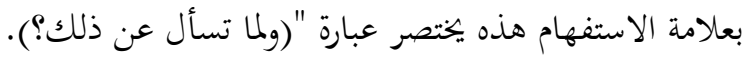
- الاكتفاء بكتابة علامة التعجب (!) عن جملة كاملة، ويحدث مداث ذلك عند الحديث عن موضع فيه تعجب فيكتفي الطرف الثاني بوضع علامة التعجب فقط دون التعبير لغة عن مشاعره واندهاشه، وقد يعمد إلى مضاعفة علامات التعجب للدلالة على شدة اندهاشه كالآتي: "!!!!!!! " . 4- شيفرة الحروف الإنجليزية: يكون ذلك بكتابة الكلمات العربية بالحروف الإنحليزية كقوله:

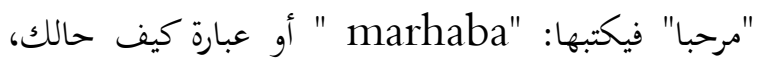
"kef halk" فيكتبها ثالثا: استخدام الصورة الرمزية في مواقع التواصل الاجتماعي ودورها في التعطيل اللغوي:

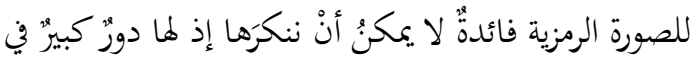
نقلِ وإيصال المشاعر والأحاسيس والعواطف بأسلوبٍ سهلٍ

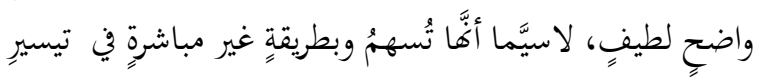

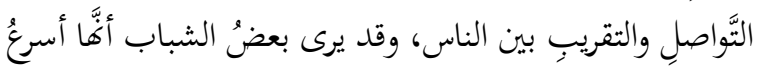

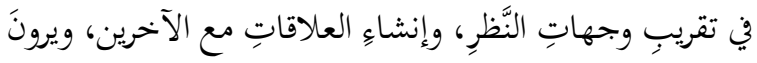

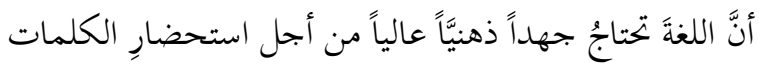

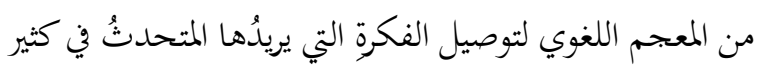

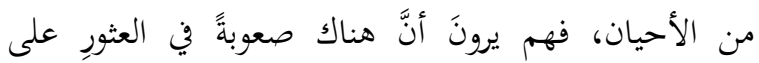
الكلمات المناسبةِ التي تسدُ تلك الثغراتِ في التعبير عن لن

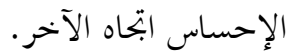

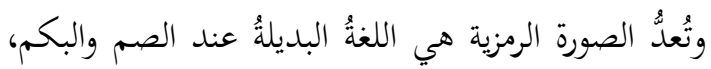

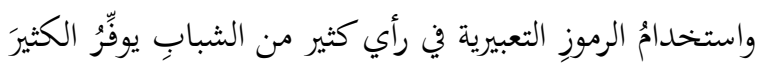

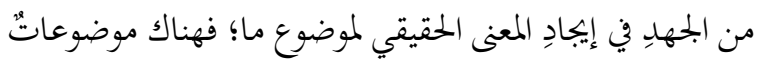

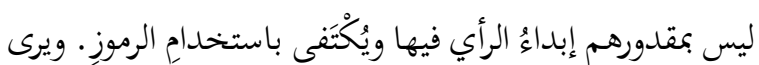

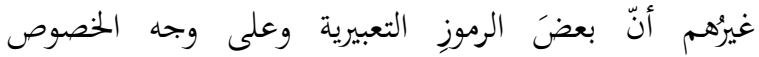
"الإيموجي" قادرةٌ على نقل لغِة الجسدِِ وتعبيراتِ الوجهِه. إضافةً

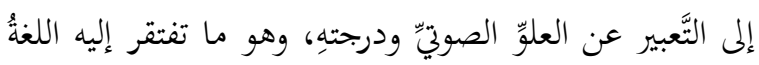

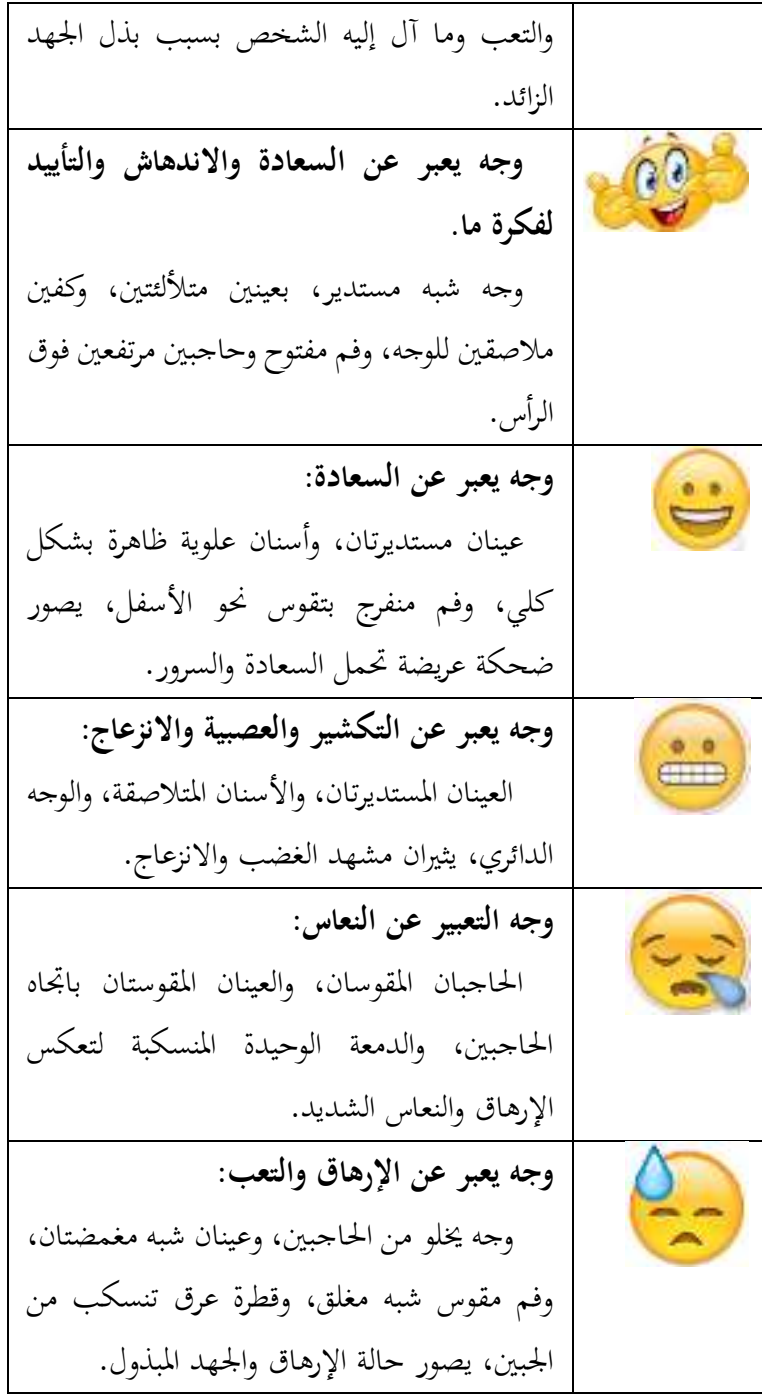

2- شيفرة تكرار الفونيمات:

تكرار فونيم اللام في اسم الجلاله (الله) لإفادة الاستغراق

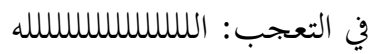

تكرار فونيم الهاء لإفادة الضحك: ه8 تكرار فونيم الفاء بعد الهمزة لإفادة كثرة التضجر والتأفف: أففففففففففف.

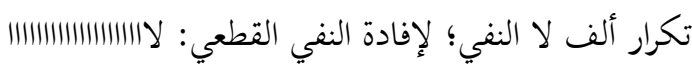

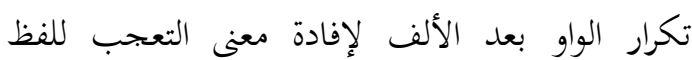
الإنجليزي ( WaW ): واوووgوووووو 3- شيفرة علامات الترقيم: ويقتصر على كتابة علامة الترقيم، عوضا عن ذكر السؤال وصياغته، توفيرا للجهد في الكتابة: - الاكتفاء بكتابة علامة الاستفهام (؟) عن ذكر السؤال، ويحدث ذلك من خلال الحوار الدائر بين الشباب، فعوضا عن 


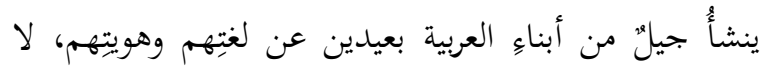

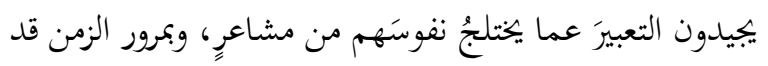

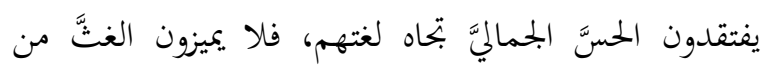

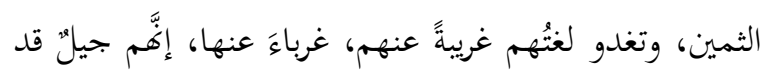

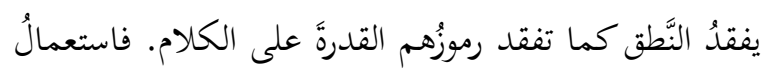

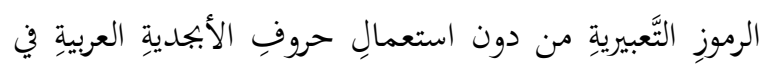

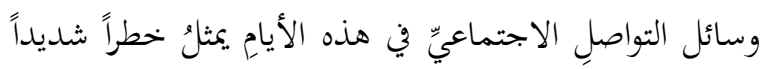

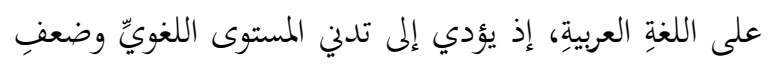
الأسلوبِ وانتشارِ الأخطاءِ الإملائيةِ واللغويةِ.

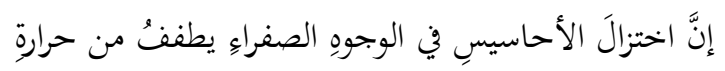

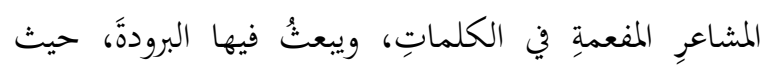

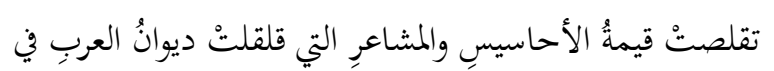

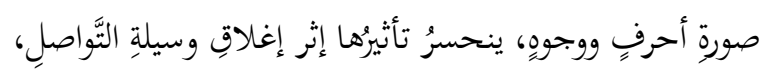

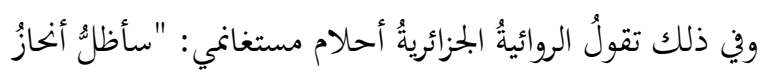

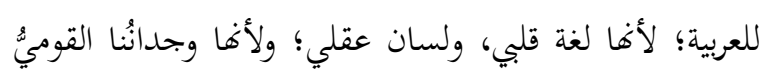

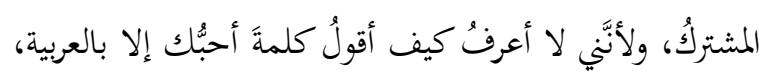

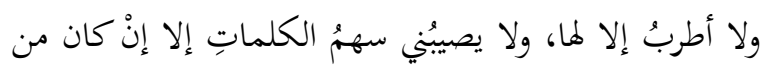

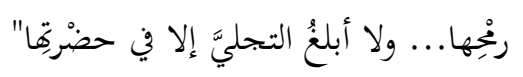

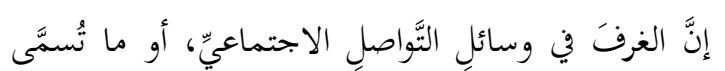

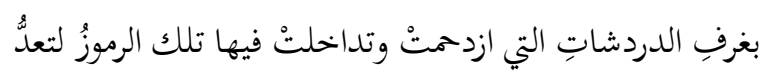

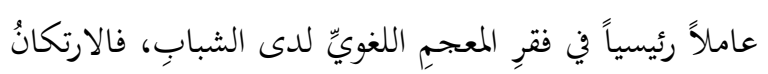

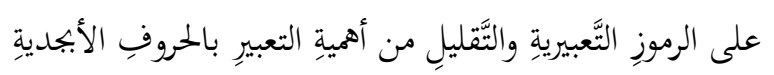

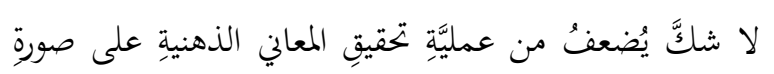

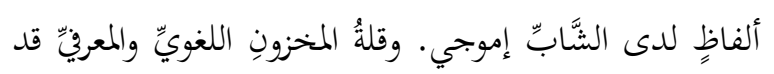

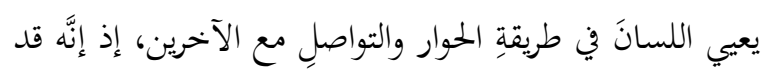

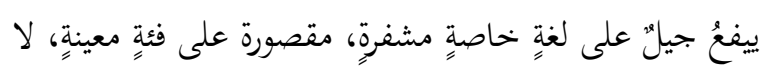
يعي قيمة لغته.

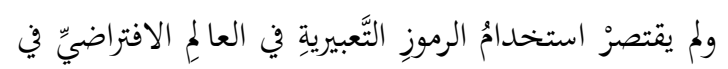

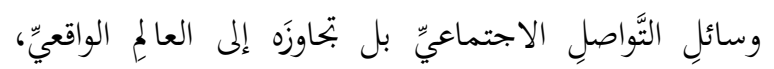

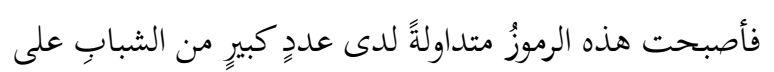

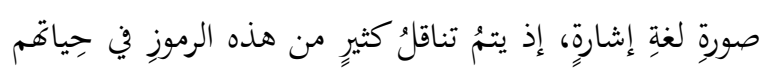

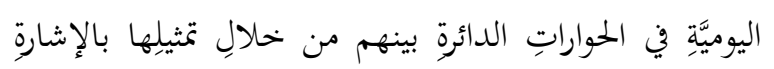

المكتوبةُ. وأنَّ استخدامَ الرموزٍ التعبيريةِ قد يفكُُّ اللَّبْسَ عن مقصودِ بعضِ الجملِِ، التي تُفهم على السخريةِ أو التهكمِّ.

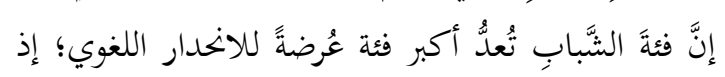

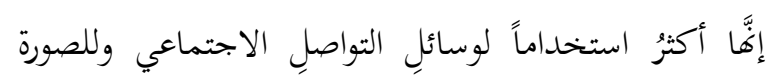

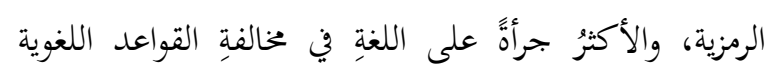

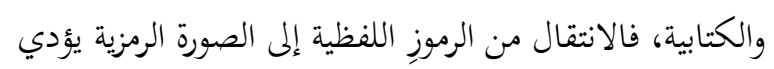

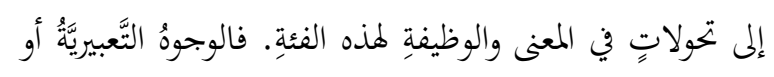

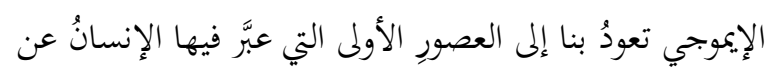

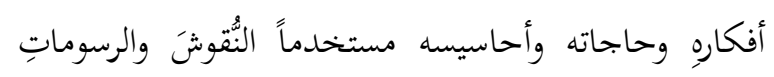

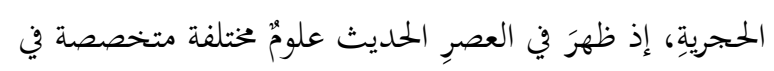

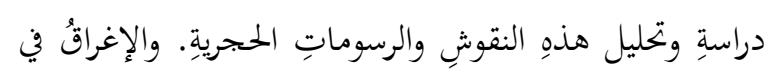

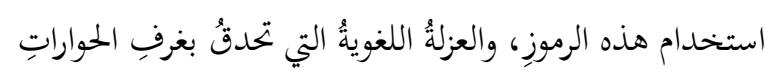

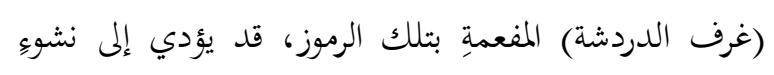

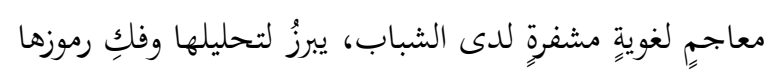

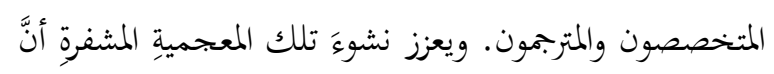

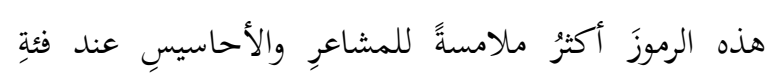
الشبابِ، فالاعتمأد الكليُّ لدى الشبابِ على رموزٍ الأزرارِ

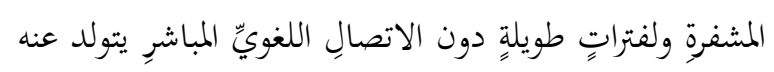

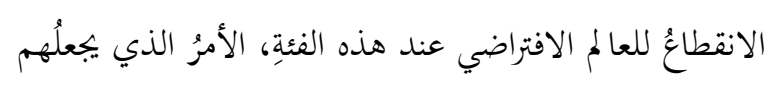

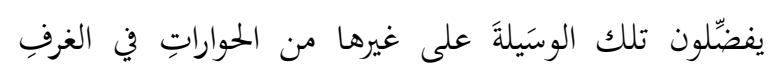
الوهمية.

وعليه يمكن القولُ إنَّ الشيفراتِ اللغويةٍ في وسائلِ التواصلِ الاجتماعي، ولَّدتْ عند فئة الشباب انطباعاتٍ سلبيةً ابحاه لغتِهم، وجعلت بعضَهم ينظرُ إلى لغتهِ بمنظارِ العجزِ وعداِ

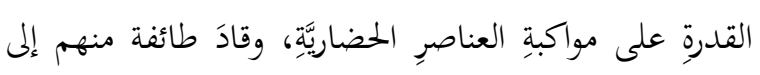

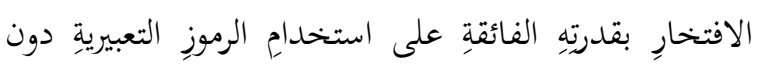

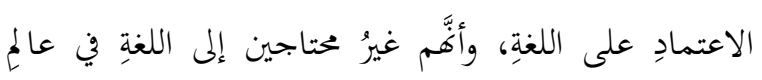

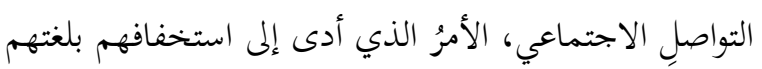

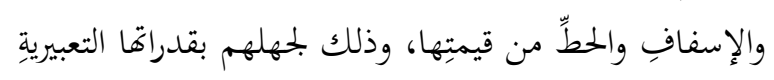
والمعجميةِ. إنَّ تفاقمَ استخدام الصورة الرمزيةٍ في وسائلِ التَّواصلِ الاجتماعيّ أمرٌ ذو مردودٍ سلبيِّ، ويحملُ من التداعياتِ الخطيرةٍ

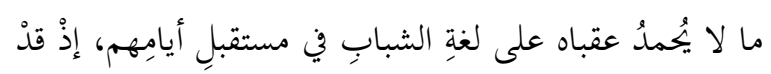


الاختصـــاص والخبرة من أعضــــاء هيئة التدريس في الجامعة،

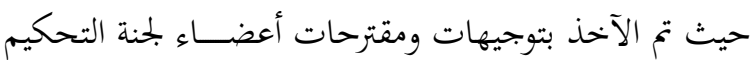
لبعض الفقرات، وذلك عندما يجمع المحكمين على ذلك.

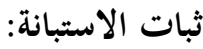

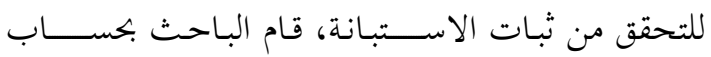
معاملات الثبات لها، بطريقتين: الأولى طريقة التطبيق وإعادة التطبيق، حيث قام الباحث بتطبيقها على عينة اســـطلاعية

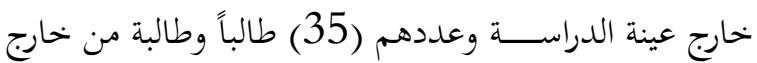

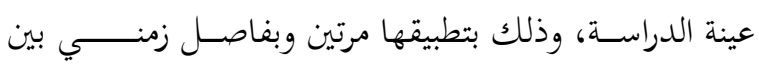

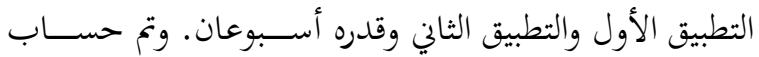

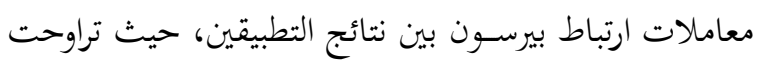

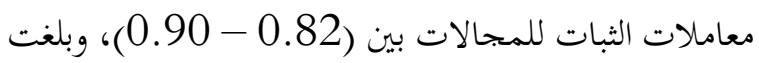
قيمة معامل الارتباط للاسـتبانة الكلية (0.92)، أما الطريقة

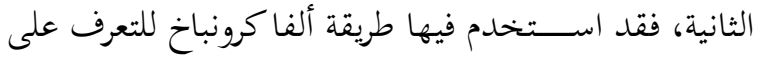
اتســاق الفقرات، فتراوحت قيم معاملات الثبات للمجالات بين (0.83 - 0.90)، و(0.91) للاسـتبانة الكلية. وهي في في قيم مقبولة لإجراء مثل هذه الدراسة.

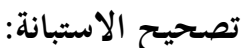

تم استخدام اسـتبانة خماسـية التدريج على شـاكلة مقياس

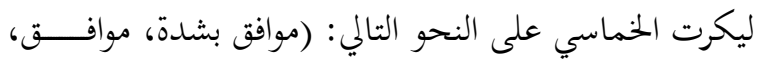

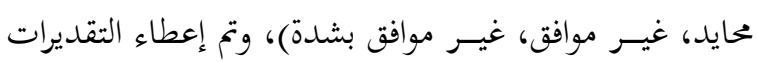

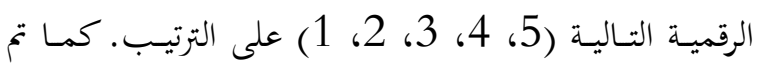

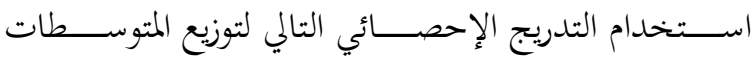

$$
\text { الحسابية: - nan }
$$
جدول رقم (1) التدريج الإحصائي لتوزيع المتوسطات المسابية

\begin{tabular}{|c|c|c|}
\hline الموافقة & الدرجة & الرقم \\
\hline قليلة جدا & 1.80 - 1.00 & 1 \\
\hline قليلة & 2.60 - 1.81 & 2 \\
\hline متوسطة & $3.40-2.61$ & 3 \\
\hline مرتفعة & 4.20 - 3.41 & 4 \\
\hline مرتفعة جدا & $5.00-4.21$ & 5 \\
\hline
\end{tabular}

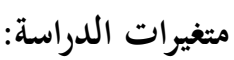

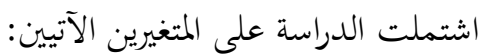

باليدينِ وإِماءاتِ الوجهِ، وهذا لا شكَُّ يُعدُّ عاملاً أشَدَ خطورةٍ

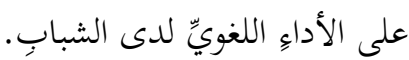

\section{الفصل الثاني: التحليل الكمي والكيفي للدراسة:} فيما يلي وصـف لمجتمع الدراسـة وعينتها، وأداة الدراسـة،

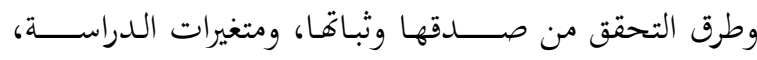
والمعالجات الإحصائية التي تم استخدامها للتوصل إلى النتائج. مجتمع الدراسة: - مجاس شمل بحتمع الدراســــة جميع طلبة أقســــام اللغة العربية في

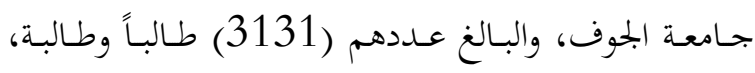
حسب إحصائيات دائرة القبول والتسجيل في الجامعة.

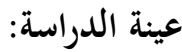
تم اختيار عينة عشوائية من بحتمع الدراسة، حيث تكونت

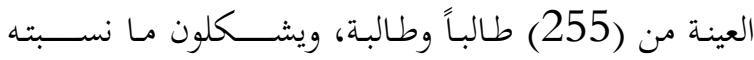

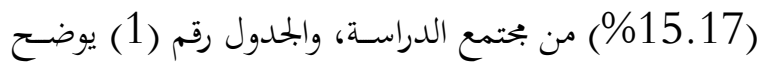
توزيع أفراد العينة حسب متغيراما. جدول (1) توزيع أفراد عينة الدراسة حسب متغيراتما

\begin{tabular}{|c|c|c|c|}
\hline النسبة المئوية & التكرار & الفئات & المتغيرات \\
\hline $42.9 \%$ & 109 & ذكور & الجنس \\
\hline $57.1 \%$ & 146 & إناث & \\
\hline $100.00 \%$ & 255 & \multicolumn{2}{|c|}{ البحموع } \\
\hline
\end{tabular}

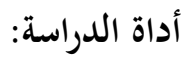

استخدم الباحث "استبانة ظاهرة استخدام الصورة الرمزية ودورها في التعطيل اللغوي لدى طلبة أقســـام اللغة العربية في جامعة الجوف، وتكونت الاستبانة من (19) فقرة موزعة على لى

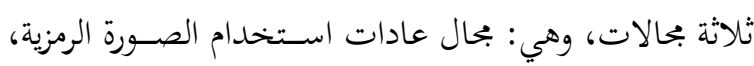

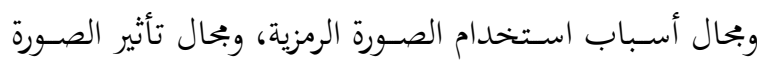
الرمزية على اللغة.

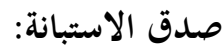

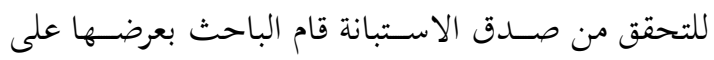

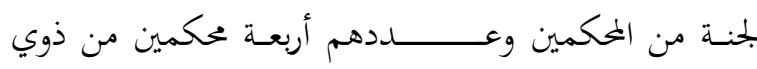




\begin{tabular}{|c|c|c|c|c|c|}
\hline درجة & الالمعياري & المتوسابي * & البحال & قلم & الرتبة \\
\hline مرتفعة & 1.17 & 3.82 & الس السباب الرمزية & 2 & 1 \\
\hline 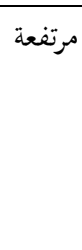 & 1.12 & 3.78 & الرادات الرميخدام & 1 & 2 \\
\hline مرتفعة & 1.18 & 3.67 & التأثير الصورة & 3 & 3 \\
\hline مرتفعة & 1.16 & 3.76 & \multicolumn{3}{|c|}{ بحالات الاستبانة ككل } \\
\hline
\end{tabular}

* الدرجة العظمى من (5)

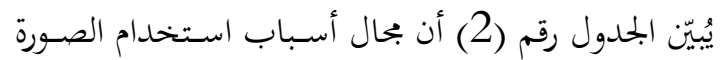

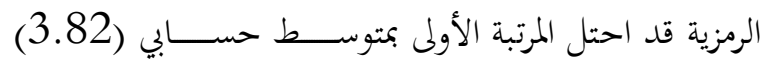

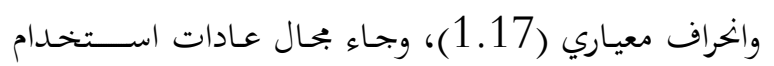

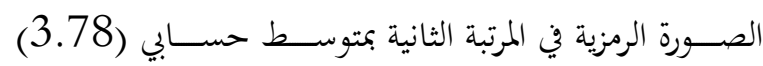
وانخراف معياري (1.12)، وجاء بحال تأثير الصورة الرمزية في

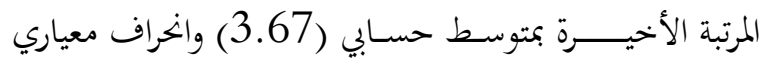

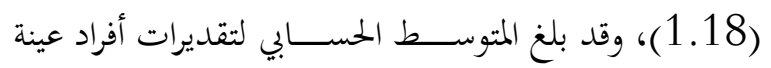

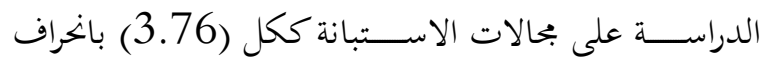
معياري (1.16)، وهو يقابل درجة تقدير مرتفعة. وقد تم

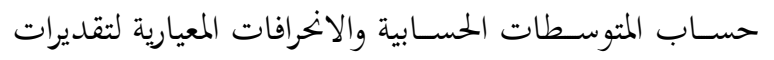
أفراد عينة الدراسة على فقرات بحالات الاستبانة، حيث كانت على النحو التالي: المجال الأول: عادات استخدام الصورة الرمزية في وسائل

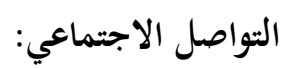
جدول (3) المتوسطات الحسابية والاخرافات المعيارية لتقديرات أفراد عينة

\begin{tabular}{|c|c|c|c|c|}
\hline \multicolumn{5}{|c|}{ راسة على بحال عضو هيئة التدريس مرتبة تنازلياً } \\
\hline درجة & الاخراف & المتوسط & الفقرات & الرقم \\
\hline الموافقة & المعياري & الحسابي" & & \\
\hline
\end{tabular}

أولاً: المتغير الوســيط وهو متغير الجنس: ولـه فئتـان، وهمـا

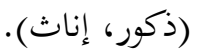
ثانياً: المتغير التابع: وهو ظاهرة اســتخدام الصــورة الرمزية في

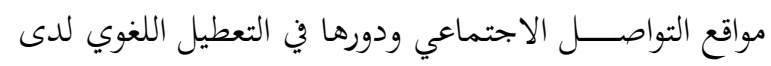

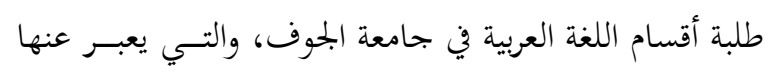
بتقديرات أفراد عينة الدراسـة على بحالات الاسـتبانة وفقراتا

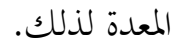
المعالجات الإحصائية: - إن

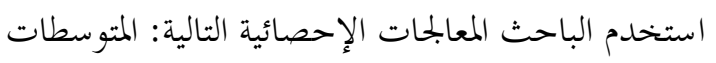
الحسابية والانخرافات المعيارية. عرض النتائج ومناقشتها: هدفت هذه الدراســة الى معرفة عادات وأســباب ظاهرة

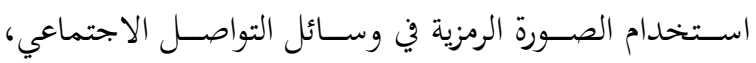

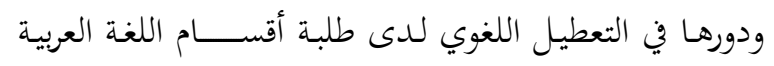

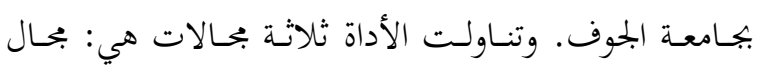

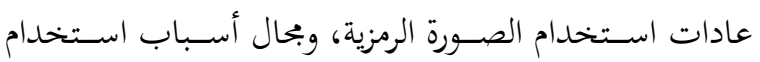
الصــورة الرمزية، وتأثير اسـتخدام الصــورة الرمزية على اللغة.

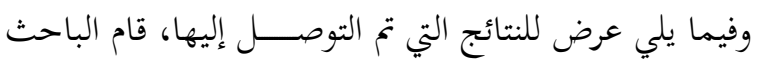

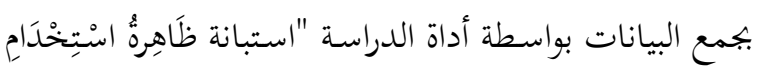

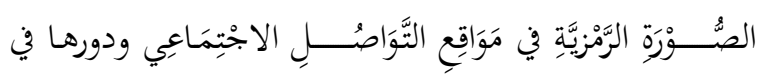

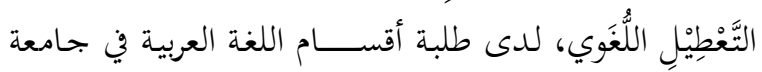
الجوف"، وقام بعرضها وفقاً لأسئلة الدراسة.

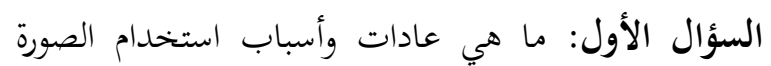

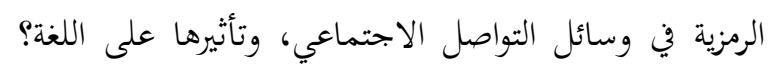

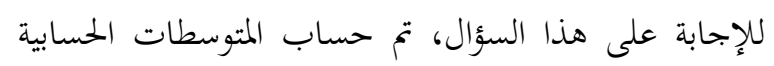

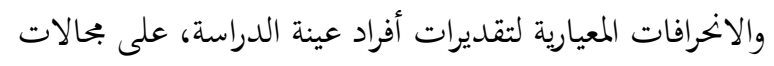

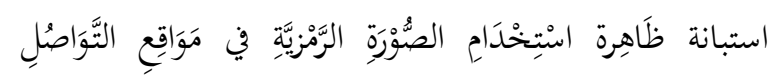

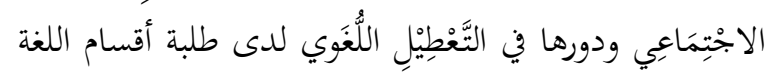
العربية في جامعة الجوف، حيث كانت كما هي موضحة في في في لئيل

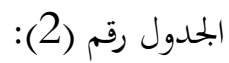
جدول (2) المتوسطات الحسابية والانرافات المعيارية لتقديرات أفراد عينة الدراسة على بحالات الاستبانة مرتبة تنازلياً 
حسابي (3.35) وبانخراف معياري(1.26) وقد بلغ المتوسط

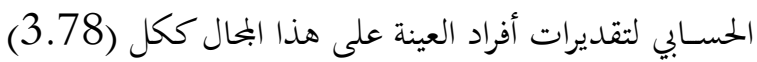
وانخراف معياري (1.12)، وهو يقابل تقدير موافقة بدرجة الثرال مرتفعة.

فاستخدام الصورة الرمزية في المحادثات اليومية وللتواصل

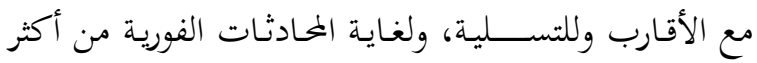

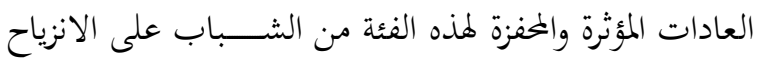

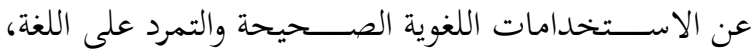

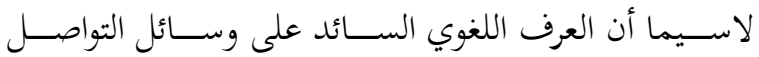

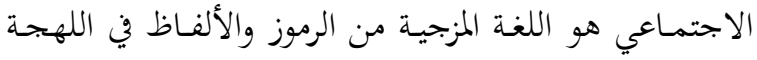

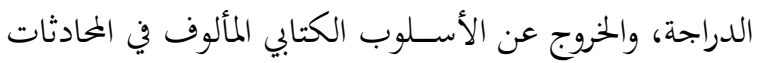

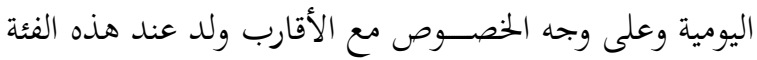

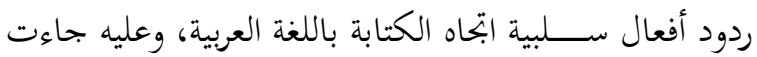

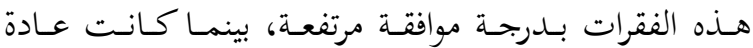

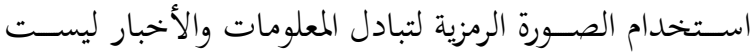
ســبـا رئيســــا وعاملا مؤثرا في التعطيل اللغوي عند العينة

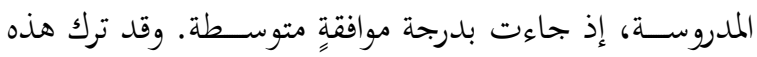

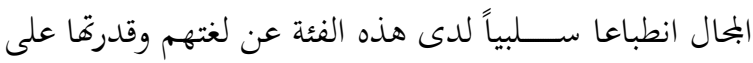
التعبير؛ وهذا يؤكد الأخذ بالفرضية الأولى. المجال الثاني: أسباب استخدام الصورة الرمزية في وسائل

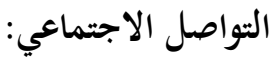
جدول (4) المتوسطات الحسابية والانحرافات المعيارية لتقديرات أفراد عينة الدراسة على بحال الطالب مرتبة تنازلياً

\begin{tabular}{|c|c|c|c|c|}
\hline الموافقة & الانحراف & المتوسط الحسابي & الفقرات & الرقم \\
\hline مرتفعة جدا & .96 & 4.33 & التسـتخدم الصـــورة & 1 \\
\hline مرتفعة & .98 & 4.20 & تســتخدم الصــورة & 2 \\
\hline مرتفعة & 1.06 & 3.98 & تالوضميز الصـورة الرمزية & 4 \\
\hline
\end{tabular}

\begin{tabular}{|c|c|c|c|c|}
\hline مرتفعة & 1.04 & 4.09 & الرمسية اليومية. & 1 \\
\hline مرتفعة & .97 & 4.07 & 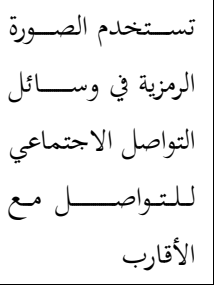 & 3 \\
\hline مرتفعة & 1.10 & 3.79 & 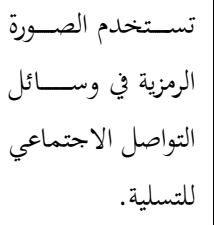 & 2 \\
\hline مرتفعة & 1.21 & 3.60 & تســتخدم الصــورة الرمزية أثناء المحادثة & 5 \\
\hline متوسطة & 1.26 & 3.35 & 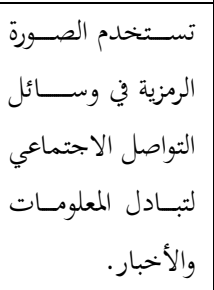 & 4 \\
\hline مرتفعة & 1.12 & 3.78 & بلجال ككل & \\
\hline
\end{tabular}

* الدرجة العظمى من (5) الدكل

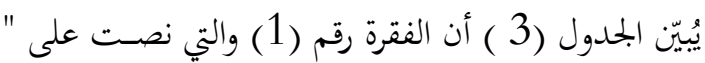

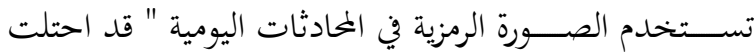
المرتبة الأولى بمتوســـ حسلــــابي (4.09) وانخراف معياري

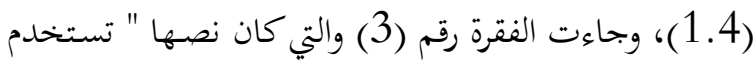

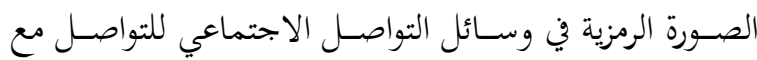

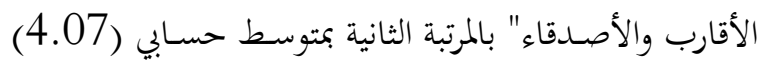
وانخراف معياري (97.)، بينما احتلت الفقرة رقم (2) والتي

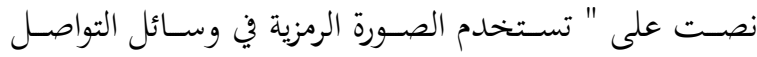
الاجتماعي للتسلية " المرتبة الثالثة بمتوسط حسابي (3.79) وانخراف معياري (1.21 )، واحتلت الفقرة رقم (5) والتي

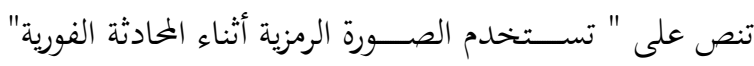

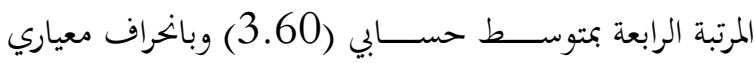

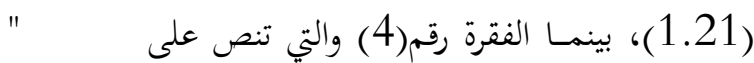
تستخدم الصورة الرمزية في وسائل التواصل الاجتماعي لتبادل

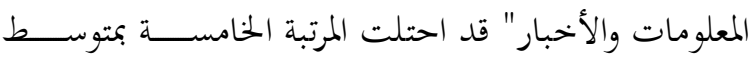


صحيح، وبعضهم يتوق إليها لأسباب اجتماعية كالنزوع نحو

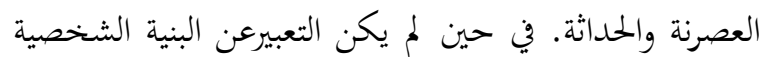
من خلال الصورة الرمزية سببا رئيسا لاستخدمها عند هذه الفئة

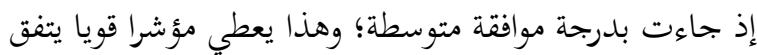

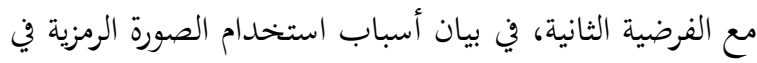

$$
\text { وسائل التواصل الاجتماعي. }
$$

وأرى أنَّ هذه الأيقوناتِ هي محاولاتُ من بعض الشبابِ

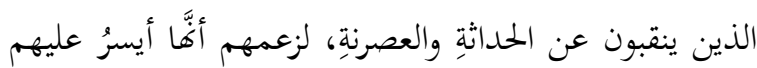

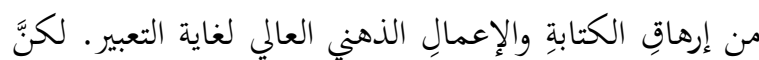

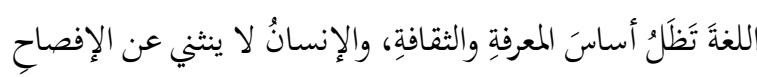
والتعبير الذي لا يتحقق إلا بالكلمةِ.

وتؤكد العينة وبدرجة موافقة مرتفعة جدا، ومرتفعة، أن الن الناكية

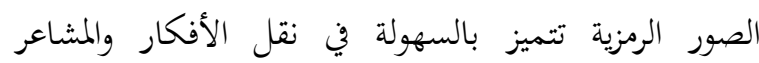

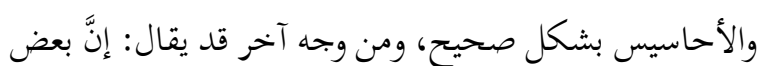

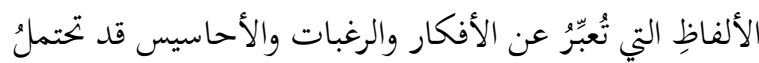

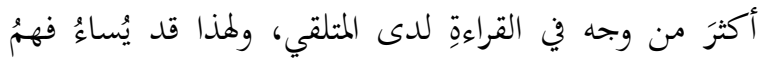

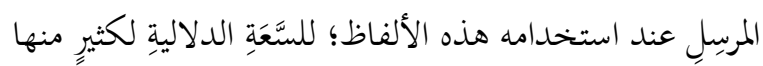

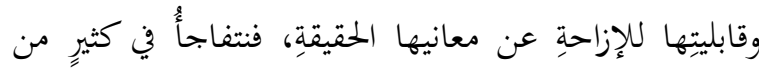

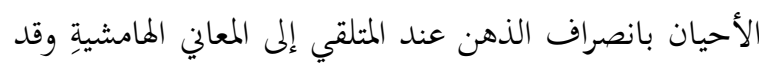

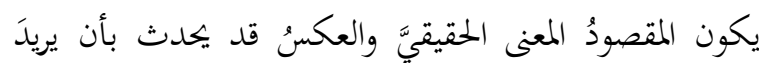

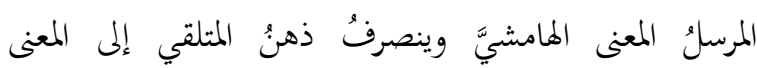

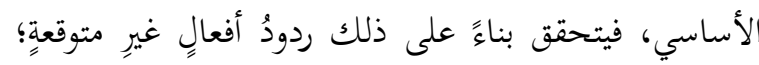

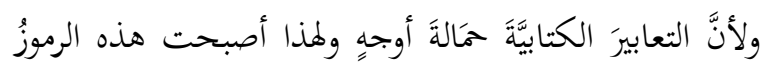

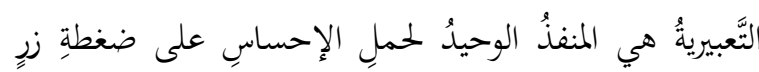
واحدةٍ.

ووجهاتُ النُّر هذه بجنعْلنُا نتساءلُ هل فعلاً أصبحت

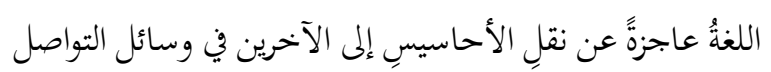

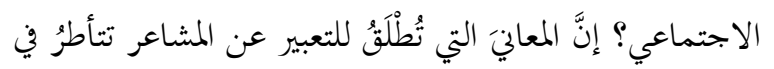

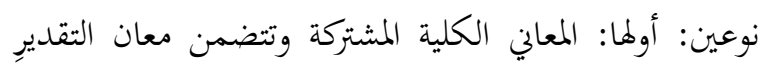

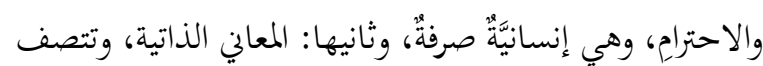

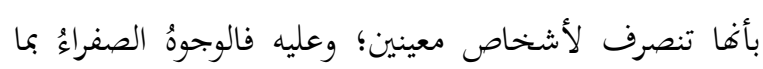

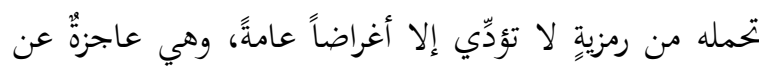

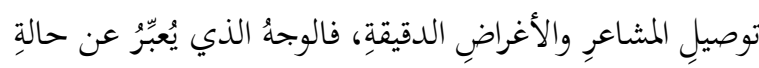

\begin{tabular}{|c|c|c|c|c|}
\hline مرتفعة & 1.07 & 3.81 & 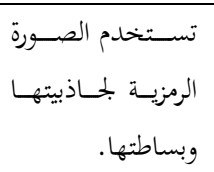 & 3 \\
\hline مرتفعة & 1.67 & 3.58 & لتسميز الصورة الرمزية & 5 \\
\hline مرتفعة & 1.20 & 3.48 & تســتخدم الصــورة الرمزية للتنقيـب عن & 7 \\
\hline متوسطة & 1.27 & 3.33 & تعبر الصــورة الرمزية & 6 \\
\hline مرتفعة & 1.17 & 3.82 & البحال ككل & \\
\hline
\end{tabular}

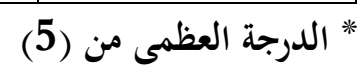

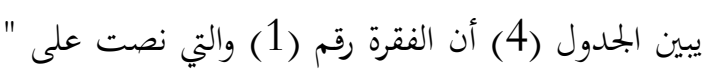

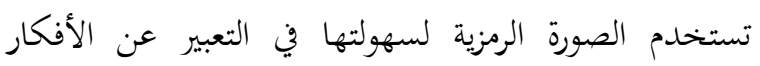
والمشاعر " قد احتلت المرتبة الأولى بكتوسط حسابي (4.33) وانراف معياري (96.)، وجاءت الفقرة رقم (2) والتي كان التمان

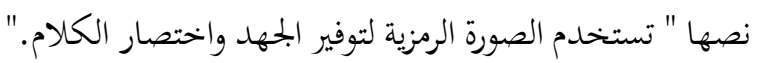

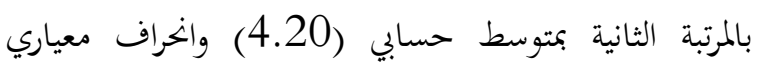
(98.)، بينما جاءت الفقرة رقم (4) والتي كان نصها " تتميز

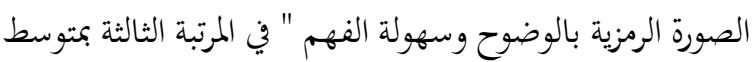
حسابي (3.98) وانخراف معياري (1.07)، بينما احتلت الفقرة السادسة والتي نصها " تعبر الصورة الرمزية عن البنية

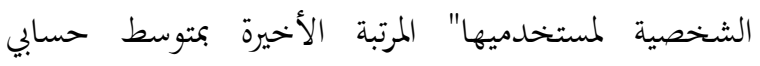

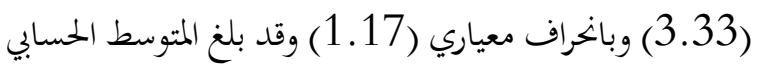

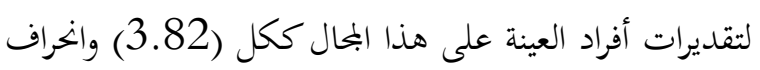
معياري (1.17)، وهو يقابل تقدير درجة مرتفعة.

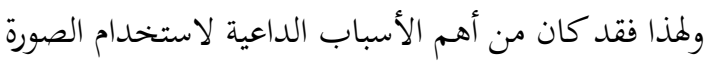

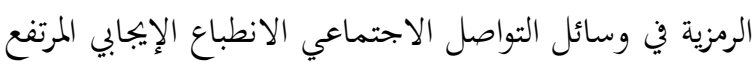

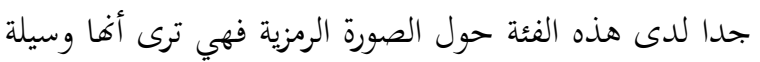

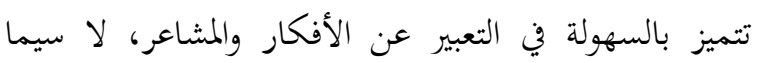
جاذبيتها وبساطتها التي أدت إلى الإغراق في استخدامها

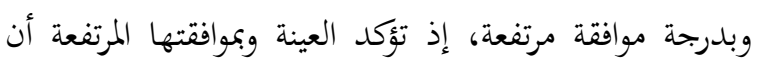

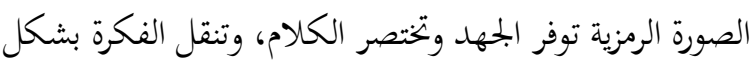




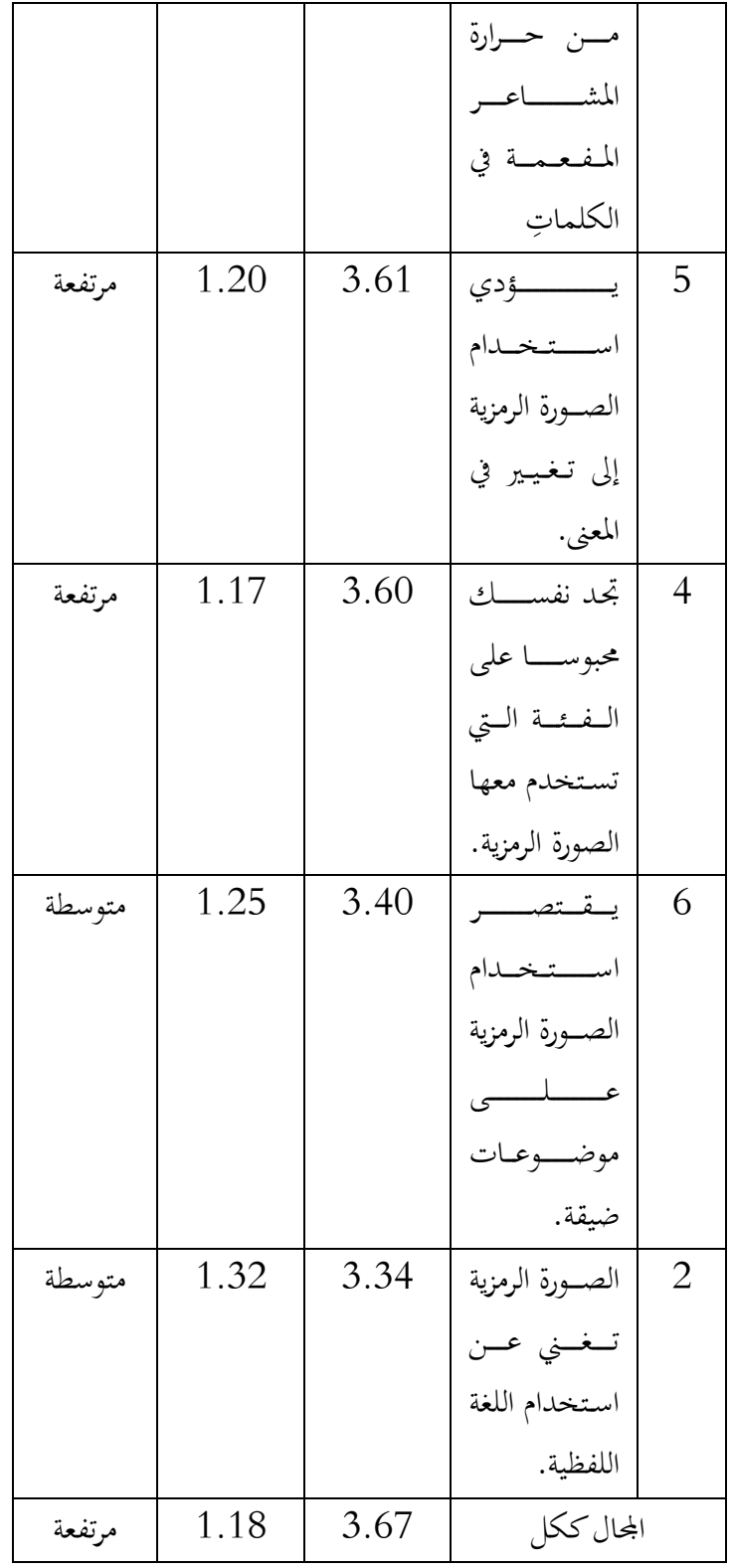

* (5) الدرجة العظمى من (5)

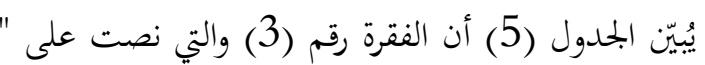

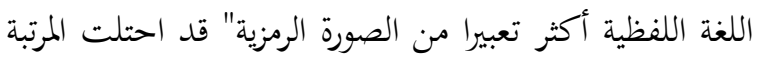
الأولى بمتوسط حسابي (4.02) وانحراف معياري (1.12)، وجاءت الفقرة رقم (1) والتي كان نصها " للرموز اللفظية تأثير قوي على الخصائص الانفعالية لمستخدمي التواصل الاجتماعي

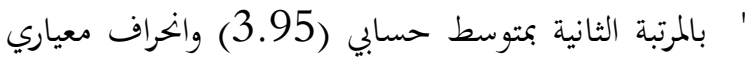

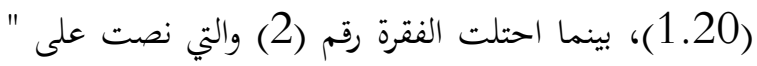

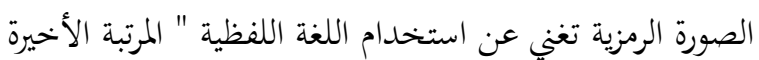

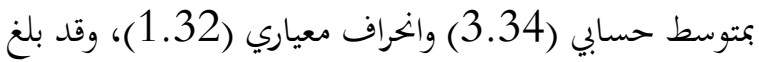
المتوسط الحسابي لتقديرات أفراد العينة على هذا المحال ككل
الحزنِ في الإيموجي مثلا إنَّا هو تعبيرٌ عامُ، لا ينبئُ عن المعاني

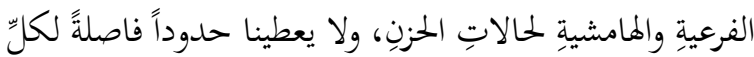
معاني الحزبِ، بل يقتصرُ على الحدّ العام له. ولهذا فهذه الوجوه الرمزية تبقى عاجزةً أمامَ البيانِ اللغويِّ،

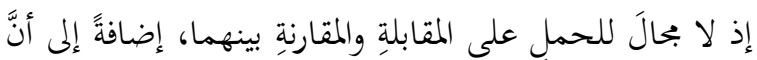
تلك الرموزَ لا تستغني في أكثرِ الحالاتِ عن ملازمةِ الفونيمات

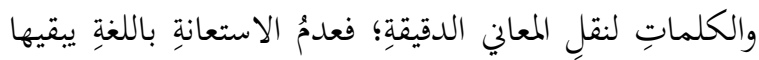

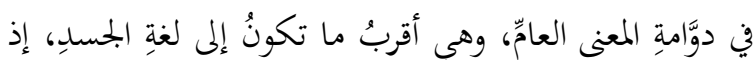

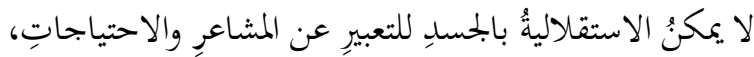

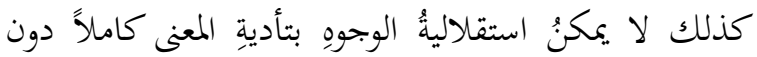

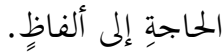

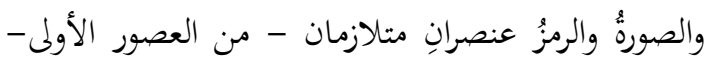
عند الإنسان، ولو أغنتْ الصورةُ لدى الإنسانِ الأوَّلِ في التعبيرِ

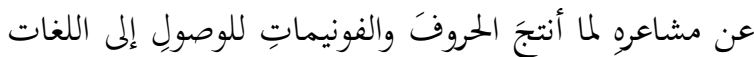

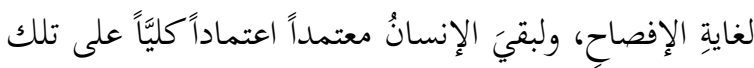
الصورِ دون الحاجةِ للغةِ، ولكنْ لملما وجدَ الإنسانُ أنَّ حاجاتِّهِ

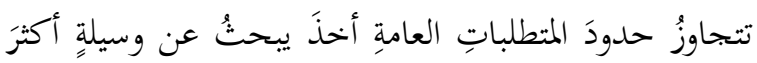
دقةٍ للتعبيرٍ عن احتياجاتِهِ الجزئيةِ والدقيقة.

\section{المجال الثالث: تأثير استخدام الصورة الرمزية على اللغة:} جدول (5) المتوسطات الحسابية والاخرافات المعيارية لتقديرات أفراد عينة الدراسة على بجال المحتوى الدراسي مرتبة تنازلياً

\begin{tabular}{|c|c|c|c|c|}
\hline المورجة & الانحراف & المتوسط & الفقرات & الرقم \\
\hline مرتفعة & 1.12 & 4.02 & أكثر تعبيرا من اللغـة اللفظيـة & 3 \\
\hline مرتفعة & 1.01 & 3.95 & 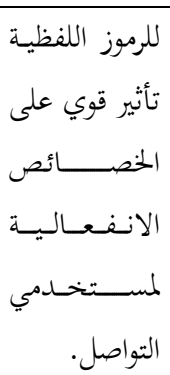 & 1 \\
\hline مرتفعة & 1.20 & 3.80 & يقلل استخدام & 7 \\
\hline
\end{tabular}


هذه الزمرةٌ التي لمُ توافق على هذه الفقرة؛ لاعتمادها الكليّ

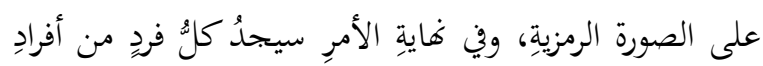

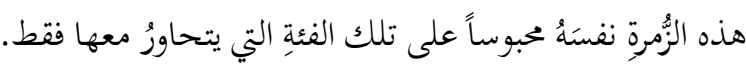

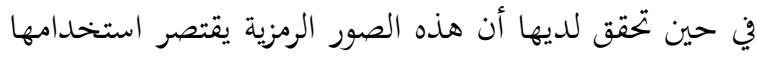
على موضوعات ضيقة بدرجة موافقة متوسطة؛ إذ لديها

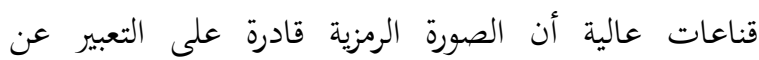
موضوعات متسعة، ودلالات عميقة وجمل وعبارات مركبة، وعليه لعب دورا مهما في التأثير اللغوي لدى أفراد العينة.

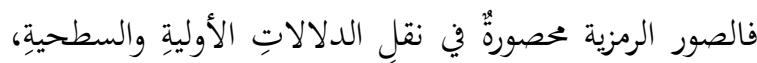

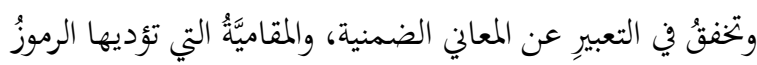

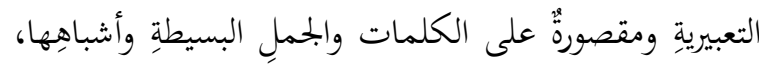

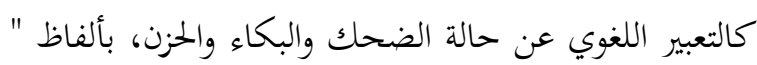

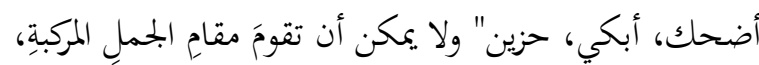

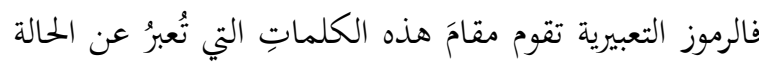

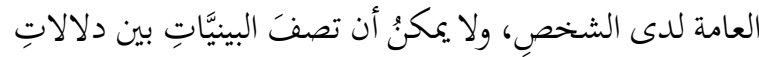

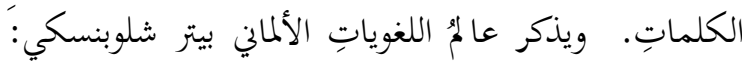

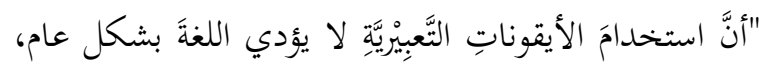

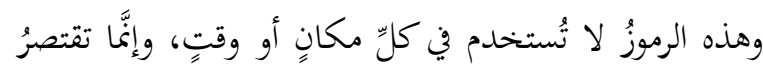

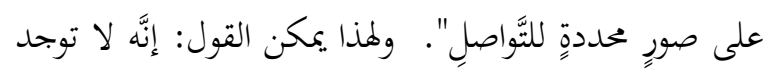

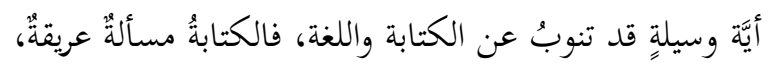

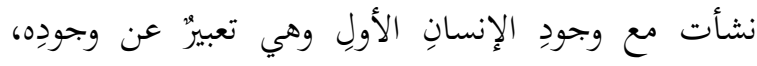
وحضارته، وتثافِته.

إنَّ أغلب الشبابِ الذين يستخدمون الصور الرمزية في مواقعَ

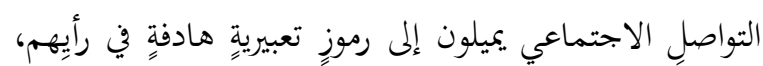

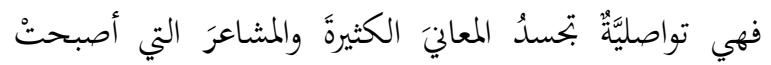

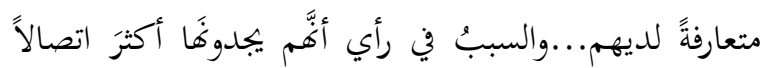

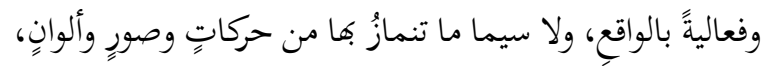

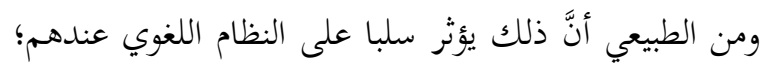

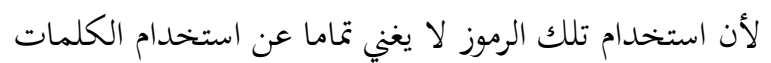

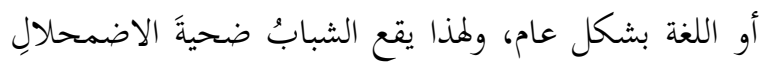
في قاموسهِ اللغويِّ. فللصورة الرمزية دوُر واضعح في تشكيلِ لغِِّ

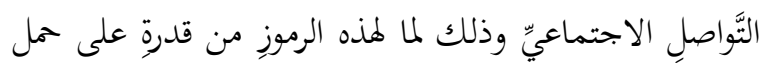

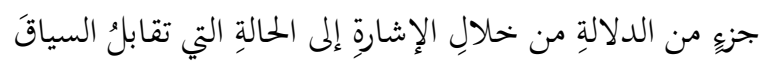

(3.67) وانحراف معياري (1.18)، وهو يقابل تقدير موافقة بدرجة مرتفعة. إن قناعات هذه الفئة عن اللغة اللفظية وسعتها التعبيرية، وتأثيرها القوي على الخصائص الانفعالية لمستخدمي الصورة الرمزية في وسائل التواصل الاجتماعي، قد أخذات درجة موافقة

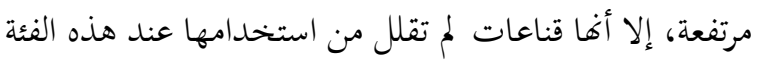

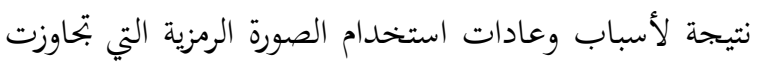

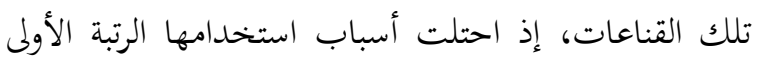

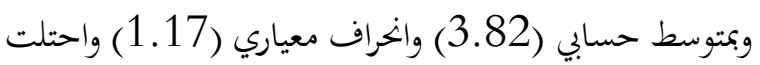
عادات استخدامها الرتبة الثانية بمتوسط حسابي (3.78) (1.78) وبانحراف معياري (1.12).

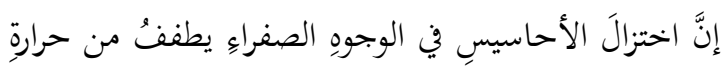

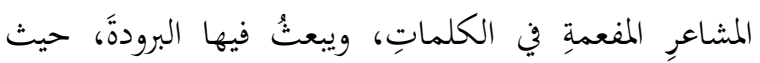

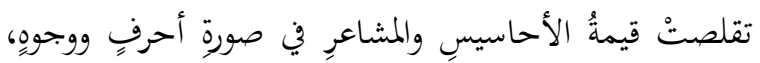

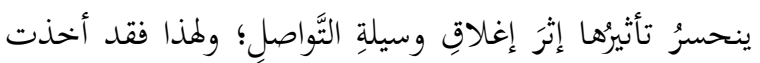

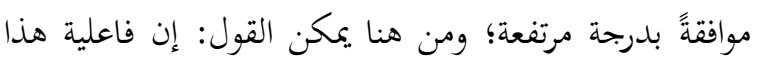
الفرض في التعطيل اللغوي ذات نسبة مئوية متدنية.

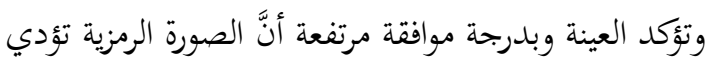

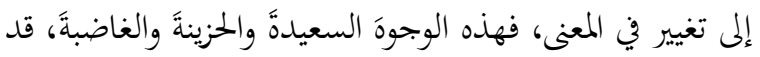

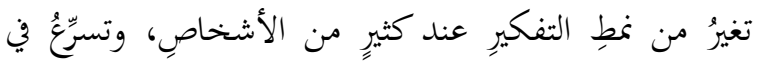
تكوينٍ الانطباعاتِ الشخصيةٍ المغلوطةٍ لدى المتلقين، إذِ قد

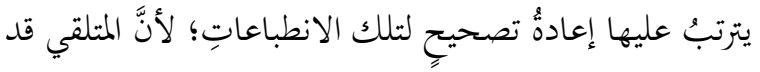

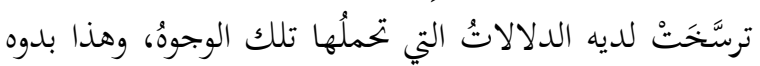

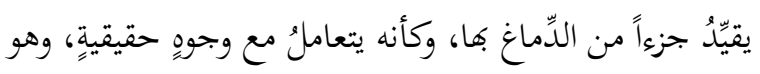

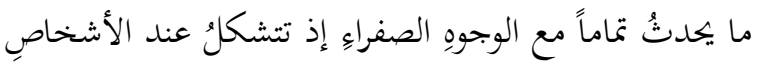

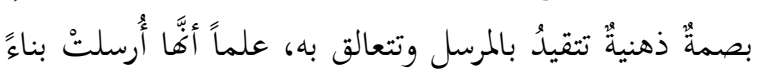

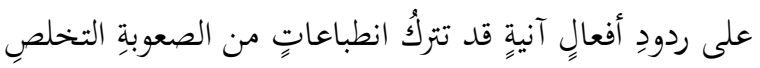

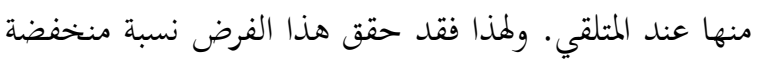
في التعطيل اللغوي لدى أفراد العينة.

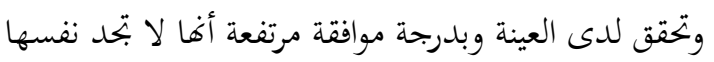

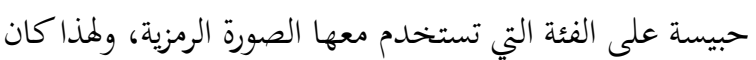

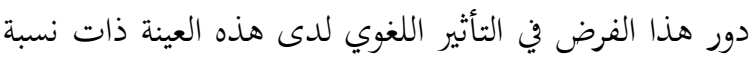

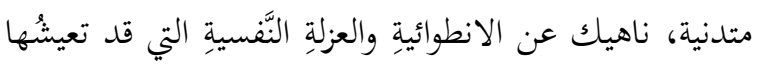


حيث احتلت الإناث المرتبة الأعلى وفق بجالات الاســـبانة بمتوسـط حسبـابي (3.88) وانحراف معياري (1.13) بينما جاءت نسـبة الذكور في المرتبة الأدنى وفق بحالات الاسـتبانة بمتوســـط حســــابي (3.66) وانخراف معيـاري (1.18). واشـــارت نتائج هذا الســـؤال إلى وجود فروق ذات دلالة

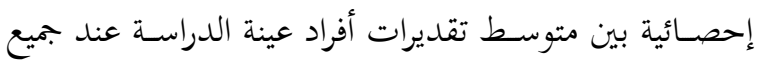
المجالات، تعزى لمتغير الجنس، وتم حساب المتوسطات الحسابية

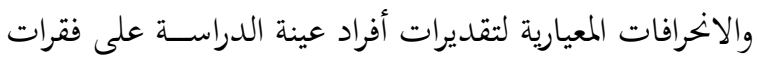
مجالات الاستبانة، حيث كانت على النحو الآتي:

المجال الأول: عادات استخدام الصورة الرمزية في وسائل

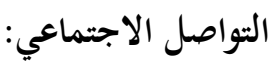
بلغت نسـبة هذا المجال عند الإناث بمتوسـط حسـابي (3.93) وبانحراف معياري (1.04) بينما بلغت نسـبته عند

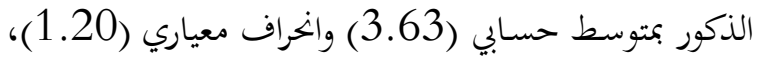

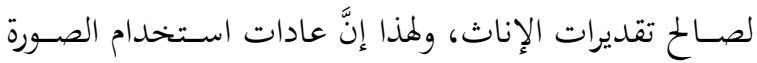

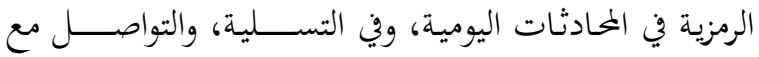

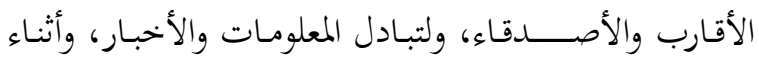
المحادثة الفورية، قد حقق نسبة مئوية عالية عند الإناث مقارنة بالذكور، وعليه فإِنَّ هذا البحال يتفق مع الفرضـــــة الأولى،

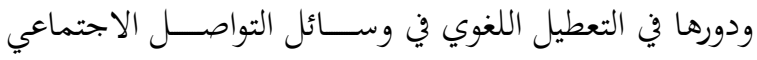
ل الصالح الإناث.

المجال الثاني: أسباب استخدام الصورة الرمزية في وسائل التواصل الاجتماعي: - (ل)

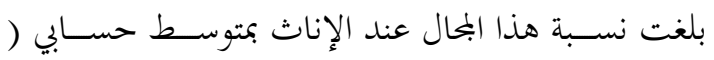
3.94) وبانحراف معياري (1.2) بينما بلغت نســـبته عند مدئ

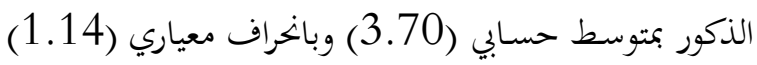
، لصالح تقديرات الإناث، وعليه فإن أسباب استخدام الصورة الرمزية في وسائل التواصل الاجتماعي لسهولتها في التعبير عن

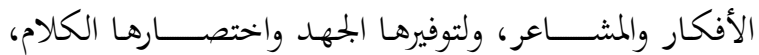

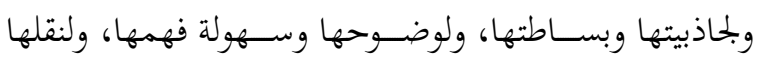

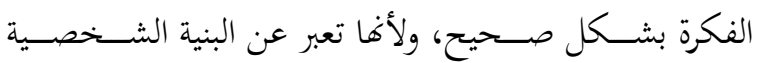

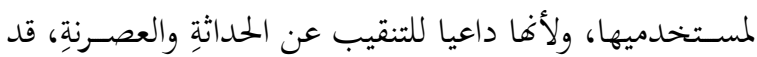

العامَ أو سياقَ الحالِِ في لغِة النَّصِ، كالغضبِ والفرحِ والحزنِ وغيرِ ذلك مما تعبر عنه تلك الرموزُ.

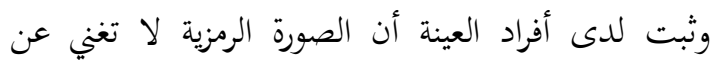
استخدام اللغة اللفظية، وقد حقق درجة موافقة متوسطة؛

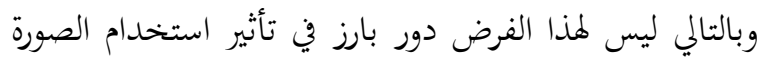

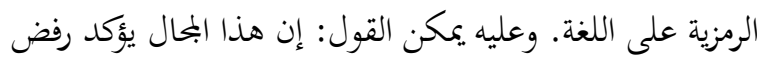
الفرضية الثالثة ودورها في التعطيل اللغوي لدى أفراد هذه العينة. الســؤال الثاني: هل توجد فروق ذات دلالة إحصــائية عند

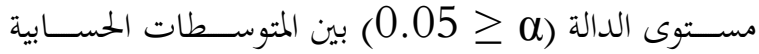

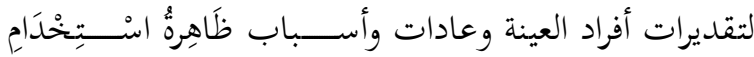

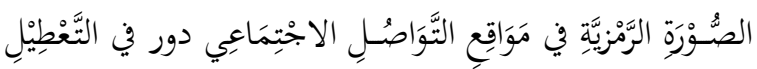

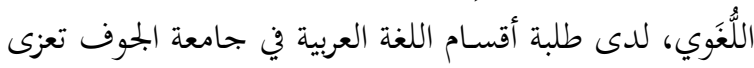
لمتغير الجنس؟ للإجابة عن هذا السؤال، تم حساب المتوسطات

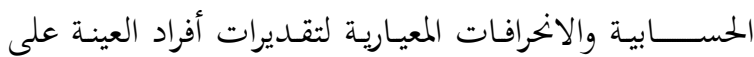

بحالات الاستبانة، حسب متغير (الجنس). جدول (6) المتوسطات الحسابية والانرافات المعيارية لتقديرات أفراد العينة

\begin{tabular}{|c|c|c|c|c|}
\hline & & & حسب مت & على بجالات الا \\
\hline$(109=$ & إناث (ن) & (146 & ذكور () & المجال \\
\hline الانخراف & المتوسط & الانخراف & المتوسط & \\
\hline المعياري & الحسابي & المعياري & الحسابي & \\
\hline 1.04 & 3.93 & 1.20 & 3.63 & عادات \\
\hline & & & & \\
\hline & & & & الصورة الرمزية. \\
\hline 1.2 & 3.94 & 1.14 & 3.70 & أسباب \\
\hline & & & & 1 \\
\hline & & & & الصورة الرمزية. \\
\hline 1.16 & 3.69 & 1.20 & 3.65 & تأثير استخدام \\
\hline & & & & الصورة الرمزية. \\
\hline 1.13 & 3.88 & 1.18 & 3.66 & الاستبانة ككل \\
\hline
\end{tabular}

يتبين من الجــداول رقم (6) وجود فروق ظـاهريـة بين المتوسطات الحسابية لتقديرات أفراد عينة الدراسة على بحالات

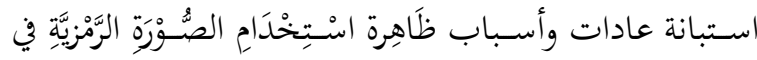

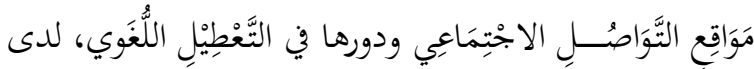

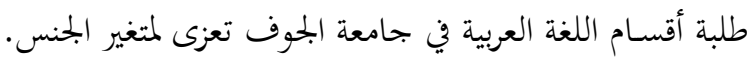


على اللغة في وسائل التواصل الاجتماعي عند أفراد العينة؛ لأنَّ

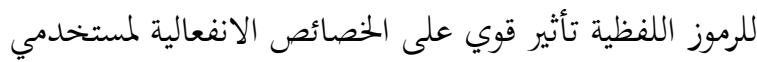

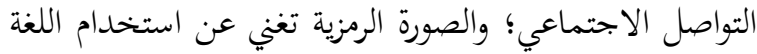
اللفظية، واللغة اللفظية أكثر تعبيرا من الصورة الرمزية، ولأن الصنان

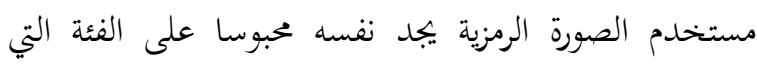

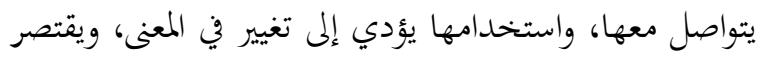

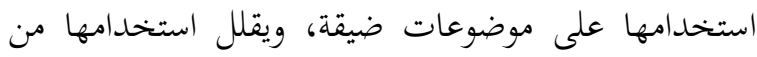
حرارة المشاعر المفعمة في الكلماتِ، ولهذا فقد حقق هذا البحال المال

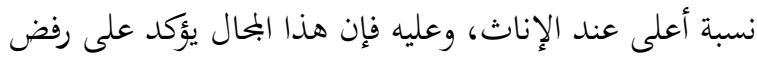
الفرضية الثالثة، ودورها في التعطيل اللغوي عند الإناث والذكور.
حققت نسبة عالية عند الإناث، وبالتالي فإن هذا البحال يتفق

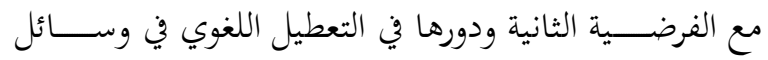
التواصل الاجتماعي لصالح الإناث. المجال الثالث: تأثير استخدام الصورة الرمزية على اللغة في وسائل التواصل الاجتماعي: بلغت نسبة هذا المجال عند الإناث بمتوسط حسابي (3.69) وبانخراف معياري (1.16) بينما بلغت نسبته عند الذكور بمتوسط حسابي (3.65) وبانراف معياري (1.18) لصالح تقدير الإناث؛ ولهذا فإن تأثير استخدام الصورة الرمزية

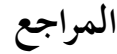

الأزهري، محمد بن أممد (2001). يتهذيب اللغة، تحقيق: محمد عوض مرعب، دار إحياء التراث العربي، بيروت، ط1، 2/ 165. ابن جني، أبو الفتح عثمان (1994م). الخصائص، ط1، القاهرة، دار الكتب العلمية، ص 568. حجازي، محمود فهمي (1973م). علم اللغة العربية، الكويت، وكالة المطبوعات، ص ص 9، 10. ابن خلدون، عبد الرمن بن محمد (1984). المقدمة، الجزائر، الدار التونسية، المؤسسة الوطنية للكتاب،2/ 722. الخولي، محمد علي (1982). معجم اللغة النظري، مكتبة لبنان.

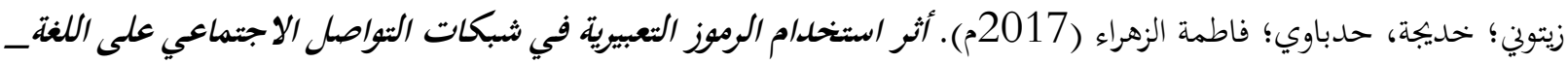

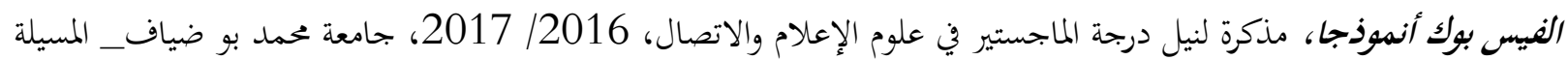

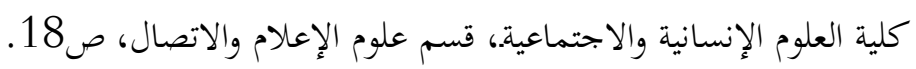

ابن سيدة، أبو الحسن علي بن إسماعيل (2000). المحكمم والمحيط الأعظم، تحقيق: عبد الحميد هنداوي، دار الكتب العلمية -

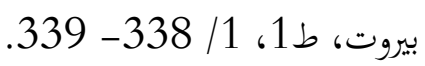

شاكر، محمود محمد (1946). اللغة والمجتمع، بحموعة مقالات، بحلة الكتاب، مج2، ص310. طعيمة؛ رشدي أممد، الناقة؛ حممود كامل (2015). مفهوم اللغة ووظائفها ، المؤتمر العلمي الدولي للغة العربية، ظاهرتا التبيان والأمن

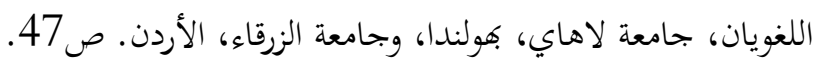

بني عطا، أممد إبراهيم (2018م). النظرية اللغوية النسبية بين التراث والدرس اللساني الحديث، بحلة البحث العلمي في

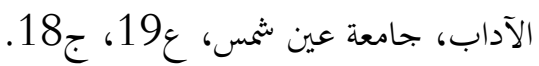




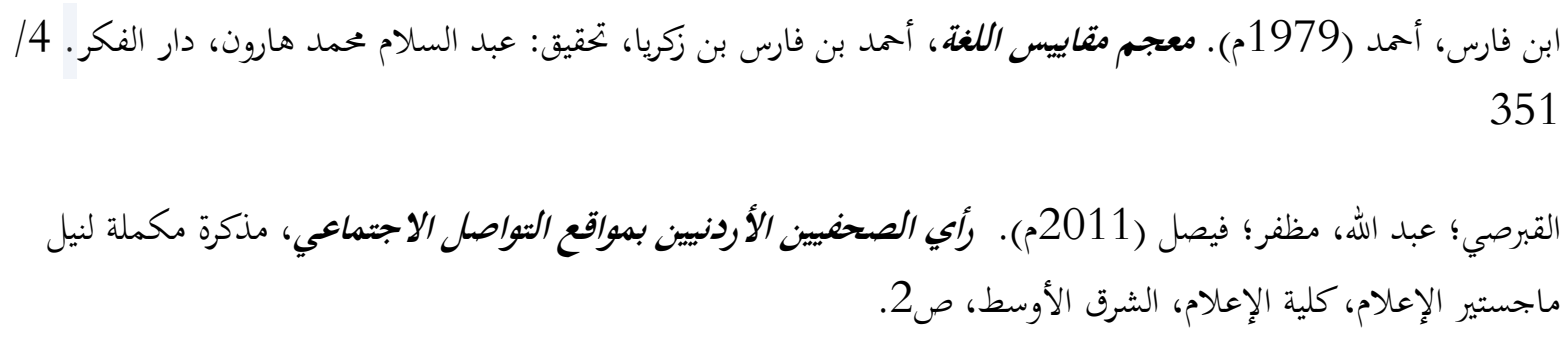

\section{المواقع على الشبكة العنكبوتية}

https://cutt.us/O3r7P :Mena Report. 12 May 2011 a 2011 https://cutt.us/neUBw تاريخ ظهور رموز الإيموجي، آخر تحديث 2019/4/3م هttps://cutt.us/XkWXd هل الإيموجي لغة العالم الجلديدة، حياة المعرفة،

https://cutt.us/nJoSM،شحيبر، محمود يوسف، الصورة المنزية في مواقع التواصل الاجتماعي، الشبكة العنكبوتية https://cutt.us/iPokK شايك وايت، إيريك سيغل (2017) The Emoji Movie مركة سوني، https://cutt.us/T3zYV أكثر الكلمات استخداما في 2015، https://cutt.us/yvAaq بالميرا ميديا، ماذا تعني أشكال الإيموجي،

Kramsky; J. (1974). The Phoneme, p41

EDWARD, S. (1921). Language an Introduction to The Study of Speech, New York: Harcourt, Brace, p32.

TRAGER, G.L. (1949). The Field of Linguistics. (SIL Occasional Papers,1) Norman Okla. Batten burg press. p 32.

N. Chomsky 1957.

Pulver Andrew (2018). The Last Knight leads worst films nominations. the Guardian. 
LiNGUA Vol. 15, No. 1, June 2020 •ISSN 1693-4725 • e-ISSN 2442-3823 